\title{
Selective phosphodiesterase inhibitors: a promising target for cognition enhancement
}

\author{
Olga A. H. Reneerkens • Kris Rutten • \\ Harry W. M. Steinbusch • Arjan Blokland • \\ Jos Prickaerts
}

Received: 30 April 2008/Accepted: 23 July 2008 / Published online: 16 August 2008

(C) The Author(s) 2008. This article is published with open access at Springerlink.com

\begin{abstract}
Rationale One of the major complaints most people face during aging is an impairment in cognitive functioning. This has a negative impact on the quality of daily life and is even more prominent in patients suffering from neurodegenerative and psychiatric disorders including Alzheimer's disease, schizophrenia, and depression. So far, the majority of cognition enhancers are generally targeting one particular neurotransmitter system. However, recently phosphodiesterases (PDEs) have gained increased attention as a potential new target for cognition enhancement. Inhibition of PDEs increases the intracellular availability of the second messengers cGMP and/or cAMP.

Objective The aim of this review was to provide an overview of the effects of phosphodiesterase inhibitors (PDE-Is) on cognition, the possible underlying mechanisms, and the relationship to current theories about memory formation.
\end{abstract}

O. A. H. Reneerkens $(\bowtie) \cdot$ K. Rutten $\cdot$ H. W. M. Steinbusch •

J. Prickaerts

Department of Neuroscience, Faculty of Health,

Medicine and Life Sciences, School for Mental Health

and Neuroscience, Maastricht University,

P.O. Box 616, 6200 MD Maastricht,

The Netherlands

e-mail: o.reneerkens@np.unimaas.nl

\footnotetext{
A. Blokland

Department of Neuropsychology and Psychopharmacology,

Faculty of Psychology and Neuroscience,

School for Mental Health and Neuroscience, Maastricht University,

Maastricht, The Netherlands
}

O. A. H. Reneerkens • K. Rutten • H. W. M. Steinbusch •

J. Prickaerts

European Graduate School for Neuroscience (EURON),

Maastricht, The Netherlands
Materials and methods Studies of the effects of inhibitors of different PDE families (2, 4, 5, 9, and 10) on cognition were reviewed. In addition, studies related to PDE-Is and blood flow, emotional arousal, and long-term potentiation (LTP) were described.

Results PDE-Is have a positive effect on several aspects of cognition, including information processing, attention, memory, and executive functioning. At present, these data are likely to be explained in terms of an LTP-related mechanism of action. Conclusion PDE-Is are a promising target for cognition enhancement; the most suitable candidates appear to be PDE2-Is or PDE9-Is. The future for PDE-Is as cognition enhancers lies in the development of isoform-specific PDE-Is that have limited aversive side effects.

Keywords PDE inhibitors · Cognition · cAMP - cGMP. Memory $\cdot$ LTP

One of the problems many people come to face as they age is a decline in cognitive functions, which has a negative impact on their daily activities and quality of life (Mattson et al. 2002). The loss of cognitive functioning is even more serious in patients suffering from pathological conditions such as Alzheimer's disease or other types of dementia. Also in depressed and schizophrenic patients, prominent cognitive deficits are present (Blaney 1986; Frith 1996). Since these deficits have a major impact on the quality life of these patients, it is of utmost importance to develop strategies or drugs that counteract cognitive decline. So far, several preventive strategies have been described which could ameliorate or slow down the cognitive decline resulting from brain aging. Research has focused on avoiding genetic and environmental factors that cause neuronal dysfunction and death or by enhancement of the ability of neurons to adapt to 
the aging process (Mattson et al. 2002). Examples of avoiding genetic factors are genetic counseling or germ line gene therapy and examples of avoiding environmental factors are dietary restrictions or behavioral modification. These strategies can induce successful aging and can reduce the risk of cognitive decline and dementia (for review, see Mattson et al. 2002). Despite these strategies, there is a great need for drugs that counteract the processes involved in aging and more specifically the decline of cognitive functions and memory.

For cognition enhancement or reversal of cognitive deficits, different drug targets have been suggested based on neurotransmitter systems. Serotonergic, cholinergic, and monoaminergic neurotransmitter systems have been shown to be involved in cognition. Furthermore, cognitive performance, including memory, can be improved by numerous biological factors such as neuromodulators, hormones, intracellular molecules, plant extracts, and nutritional ingredients, which enhance neurotransmission, blood flow, glucose metabolism, or have free radical scavenging properties (Cahill et al. 1994; Davis and Squire 1984; DeZazzo and Tully 1995; Izquierdo et al. 1998; McGaugh 1989; Messier 2004; Parrott et al. 2004).

\section{Second messengers cAMP and cGMP}

A relatively novel and promising field in cognition research focuses on the involvement of second messenger systems. Neurotransmitter receptors can be divided into two main groups according to the way in which receptor and effector function are coupled. One group consists of ionotropic (ion channel) receptors and the other consists of the GTP-binding protein (G protein) coupled receptor. $G$ protein activation engages second messenger cascades (Shah and Catt 2004). Traditionally, the cyclic adenosine monophosphate (cAMP) second messenger system (Gs and Gi linked) and the phosphoinositol second messenger system (Gq-linked) received the most attention. The second messenger cAMP is synthesized by adenylate cyclase (AC), which is stimulated or inhibited by Gs or Gi, respectively. The second messenger complex inositol-1,4,5, triphosphate/diacylglycerol (IP3/ DAG) is formed out of the hydrolysis of phosphatidylinositol 4,5-biphosphate (PIP2) by phospholipase C (PLC) after activation by Gq. cAMP activates cAMP-dependent protein kinase (PKA), which phosphorylates cAMP response element-binding protein (CREB). P-CREB is an activated transcription factor, which initiates transcription of specific genes. DAG activates calcium-dependent protein kinase (PKC) in the presence of calcium $\left(\mathrm{Ca}^{2+}\right)$, which is mobilized by IP3. PKC has an effect on CREB via the MAP kinase pathway. Of note, $\mathrm{Ca}^{2+}$ can also bind to calmodulin. This so-called $\mathrm{Ca}^{2+} / \mathrm{CaM}$ complex activates $\mathrm{Ca}^{2+} / \mathrm{CaM}$ protein kinase $(\mathrm{CaMK})$, which can activate calcium-dependent protein kinase (PKC) as well, but also PKA. On the other hand, PKA can also activate the MAP kinase pathway. Thus, interplay exists between the cAMP second messenger system and the phosphoinositol second messenger system. Recently, the cyclic guanosine monophosphate (cGMP) second messenger system receives more and more attention. cGMP is produced by guanylate cyclase (GC) which is stimulated by nitric oxide (NO) (Murad et al. 1978). cGMP activates cGMP-dependent protein kinase (PKG), which in turn phosphorylates certain proteins which influence the synthesis and/or release of other neurotransmitters, and thus signal transduction (Schmidt et al. 1993).

Cyclic nucleotide phosphodiesterases (PDEs) are enzymes which play an important role in the abovementioned intracellular signal transduction pathways. This is because these enzymes hydrolyze the second messengers cAMP and cGMP by breaking their phosphodiester bond with the corresponding monophosphate (Bender and Beavo 2006). There are 11 families of PDEs (PDE1-PDE11) and most of these families have more than one gene product (e.g., PDE4A, PDE4B, PDE4C, PDE4D). In addition, each gene product may have multiple splice variants (e.g., PDE4D1-PDE4D9). In total, there are more than 100 specific human PDEs (Bender and Beavo 2006).

\section{Localization of PDEs}

PDE1 is predominantly localized in the brain, heart, smooth muscles, and lungs (Dent et al. 1998; Sonnenburg et al. 1998; Yan et al. 1994). In addition, PDE2 can be found in the brain, heart, adrenal cortex, and platelets (Ito et al. 1996; Martins et al. 1982; Van Staveren et al. 2003). Furthermore, the localization of PDE3 includes the brain, heart, smooth muscles, kidneys, and platelets (Reinhardt et al. 1995; Shakur et al. 2001). PDE4 is expressed in a wide variety of tissues, e.g., brain, lungs, and testes (Perez-Torres et al. 2000; Reyes-Irisarri et al. 2008; Richter et al. 2005; Salanova et al. 1999). PDE5 has been detected in the brain, lungs, smooth and skeletal muscles, kidneys, and platelets (Giordano et al. 2001; Hotston et al. 2007; Kotera et al. 2000; Yanaka et al. 1998). In contrast, PDE6 has been found in the pineal gland and the rod and cone cells of the photoreceptor layer of the retina (Holthues and Vollrath 2004; Morin et al. 2001; Stearns et al. 2007). PDE7 was identified in the brain, heart, liver, skeletal muscles, kidneys, testes, and pancreas (Hetman et al. 2000; Miro et al. 2001), while the localization of PDE8 includes the brain, liver, kidneys, colon, testes, ovary, spleen, and thyroid (Fisher et al. 1998a; Gamanuma et al. 2003; Hayashi et al. 1998, 2002; Kobayashi et al. 2003; Soderling et al. 1998; Wang et al. 2001). Also, PDE9 is located in the brain, kidneys, spleen, prostate, and various gastrointestinal tissues (Andreeva et al. 2001; Fisher et al. 1998b; Rentero 
et al. 2003; Soderling et al. 1998; van Staveren and Markerink-van Ittersum 2005; Van Staveren et al. 2003; Wang et al. 2003). The localization of PDE10 comprises the brain, heart, muscles, testes, and thyroid (Fujishige et al. 1999; Loughney et al. 1999; Soderling et al. 1999). And finally, it has been shown that PDE11 is primary located in the pituitary, liver, skeletal muscles, kidneys, testes, prostate, and thyroid (Fawcett et al. 2000).

The localizations of the different PDE isoforms differ between specific brain areas as is illustrated in detail in Table 1. Since PDEs are involved in the regulation of second messenger signaling in numerous important body and brain structures, specific inhibitors of the PDE families have been generated. PDE inhibitors (PDE-Is) increase the intracellular amount of cAMP and/or cGMP by inhibiting the enzymatic degradation of these second messengers, dependent on the substrate specificity of the corresponding PDE (see also Table 2). Several selective PDE-Is and the substrate, i.e., cAMP and/or cGMP, of their target PDEs are classified in Table 2.
By far, not all classes of PDEs have selective inhibitors. In addition, these inhibitors might have poor penetration properties concerning the blood-brain barrier. In the literature, only five PDE-Is have been implicated in behavioral cognition studies, namely, PDE 2, 4, 5, 9, and 10 inhibitors, as will become evident in this review. These inhibitors are widely available, can be administered peripherally, and show central effects. The existing literature on PDE-Is and cognition is rapidly emerging and procognitive effects of PDE-Is have been described in fish, rodents, monkeys, and man (e.g., Best et al. 2008; Rutten et al. 2007b, 2008a; Schultheiss et al. 2001). Studies were conducted to asses the effects of PDE-Is on intact cognition as well as in cognitive deficit models. In addition, knockout models have been developed to study the role of PDEs in cognition processes. This review provides a comprehensive overview of the currently available literature on the effects of selective PDE-Is on cognition in preclinical models. Furthermore, possible implications for human studies are discussed. Finally, the underlying mechanisms of action for the procognitive effects of PDE-Is are

Table 1 Localization of the different PDE isoforms in the adult brain of rodents and humans

\begin{tabular}{|c|c|c|c|}
\hline Isoform & Localization in the brain & Species & Reference \\
\hline PDE1A & $\begin{array}{l}\text { Hippocampus, cortex, olfactory bulb, striatum, } \\
\text { thalamus, cerebellum }\end{array}$ & Human, rat, mouse & $\begin{array}{l}\text { Billingsley et al. (1990); Cho et al. (2000); } \\
\text { Lal et al. (1999); Yan et al. (1994) }\end{array}$ \\
\hline PDE1B & $\begin{array}{l}\text { Hippocampus, cortex, olfactory bulb, } \\
\text { striatum }\end{array}$ & Mouse, rat & $\begin{array}{l}\text { Cho et al. (2000); Polli and Kincaid (1994); } \\
\text { Reed et al. (1998) }\end{array}$ \\
\hline PDE1C & Hippocampus, cortex, amygdala, cerebellum & Mouse & Yan et al. (1996) \\
\hline PDE2A & $\begin{array}{l}\text { Hippocampus, cortex, striatum, amygdala, } \\
\text { hypothalamus, midbrain }\end{array}$ & Human, rat, mouse & $\begin{array}{l}\text { Bolger et al. (1994); Repaske et al. (1993); } \\
\text { Reyes-Irisarri et al. (2007); van Staveren et al. } \\
(2004,2003)\end{array}$ \\
\hline PDE3 & Throughout the brain & Rat & Bolger et al. (1994) \\
\hline PDE4A & $\begin{array}{l}\text { Hippocampus, cortex, olfactory bulb, striatum, } \\
\text { thalamus, hypothalamus, amygdala, midbrain, } \\
\text { cerebellum }\end{array}$ & Human, rat, mouse & $\begin{array}{l}\text { Braun et al. (2007); Cherry and Davis (1999); } \\
\text { Cho et al. (2000); D’Sa et al. (2005); Fujita } \\
\text { et al. (2007) }\end{array}$ \\
\hline PDE4B & $\begin{array}{l}\text { Hippocampus, cortex, striatum, hypothalamus, } \\
\text { midbrain, cerebellum }\end{array}$ & Human, rat, mouse & $\begin{array}{l}\text { Braun et al. (2007); Cherry and Davis (1999); } \\
\text { Cho et al. (2000); Fujita et al. (2007) }\end{array}$ \\
\hline PDE4D & $\begin{array}{l}\text { Hippocampus, cortex, striatum, hypothalamus, } \\
\text { midbrain, cerebellum }\end{array}$ & Human, rat, mouse & $\begin{array}{l}\text { Cherry and Davis (1999); Cho et al. (2000); } \\
\text { Fujita et al. (2007); McLachlan et al. (2007); } \\
\text { Richter et al. (2005) }\end{array}$ \\
\hline PDE5A & Hippocampus, cortex, cerebellum & Human, rat, mouse & $\begin{array}{l}\text { Reyes-Irisarri et al. (2007); van Staveren et al. } \\
(2004,2003)\end{array}$ \\
\hline PDE7A & Hippocampus, cortex, olfactory bulb, striatum & Human, rat & Miro et al. (2001); Perez-Torres et al. (2003) \\
\hline PDE7B & Hippocampus, cortex, striatum, midbrain & Human, rat & Perez-Torres et al. (2003); Sasaki et al. (2002) \\
\hline PDE8B & $\begin{array}{l}\text { Hippocampus, cortex, olfactory bulb, striatum, } \\
\text { midbrain }\end{array}$ & Human, rat & Kobayashi et al. (2003); Perez-Torres et al. (2003) \\
\hline PDE9A & $\begin{array}{l}\text { Hippocampus, cortex, olfactory bulb, striatum, } \\
\text { thalamus, hypothalamus, amygdala, midbrain, } \\
\text { cerebellum }\end{array}$ & Human, rat, mouse & $\begin{array}{l}\text { Reyes-Irisarri et al. (2007); van Staveren et al. } \\
(2004,2003)\end{array}$ \\
\hline PDE10 & $\begin{array}{l}\text { Hippocampus, cortex, striatum, midbrain, } \\
\text { cerebellum }\end{array}$ & Rat & Seeger et al. (2003) \\
\hline
\end{tabular}

Note that this table does not provide information with respect to the level of expression of the different isoforms in the brain. In addition, expression can implicate mRNA levels or protein levels dependent on the study referred to 
Table 2 Overview of PDEs

\begin{tabular}{lclll}
\hline Type & Number of genes & Property & Substrate & Selective inhibitors \\
\hline PDE1 & 3 & Ca ${ }^{2+}$-CaM-stimulated & cAMP/cGMP & $\begin{array}{l}\text { IBMX, calimidazolium, phenethiazines, vinpocetine, } \\
\text { SCH51866 } \\
\text { PDE2 }\end{array}$ \\
PDE3 & 2 & $\begin{array}{l}\text { cGMP-stimulated } \\
\text { cGMP-inhibited }\end{array}$ & $\begin{array}{l}\text { cAMP/cGMP } \\
\text { cAMP }\end{array}$ & $\begin{array}{l}\text { CHNA, BAY 60-7550, aptosyn } \\
\text { Cilostamide, milrinone, SK\&F 95654 }\end{array}$ \\
PDE4 & 4 & cAMP-specific & cAMP & Rolipram, rofluminast, ariflo, HT0712, ibudilast, mesembrine \\
PDE5 & 1 & cGMP-specific & cGMP & $\begin{array}{l}\text { Zaprinast, sildenafil, vardenafil, tadelafil, SK\&F 96231, } \\
\text { udenafil, avanafil, DA-8159 }\end{array}$ \\
PDE6 & 4 & Photoreceptor & cGMP & (Sildenafil) \\
PDE7 & 2 & cAMP high affinity & cAMP & BRL 50481 \\
PDE8 & 2 & cAMP high affinity & cAMP & $?$ \\
PDE9 & 1 & cGMP high affinity & cGMP & SCH 81566, BAY 73-6691 \\
PDE10 & 1 & cAMP-inhibited & cGMP & Papaverine, TP-10, PQ10 \\
PDE11 & 1 & Dual substrate & cAMP/cGMP & (Tadelafil) \\
\hline
\end{tabular}

The properties and substrate specificity are depicted (Bender and Beavo 2006). In addition, commonly used selective PDE inhibitors are mentioned

$P D E$ phosphodiesterase, $c A M P$ cyclic adenosine monophosphate, $c G M P$ cyclic guanosine monophosphate

discussed and a concomitantly novel theory describing the relationship between different stages of memory consolidation and different types of long-term potentiation (LTP) is proposed.

\section{Effects of selective PDE-Is on cognition}

\section{PDE2}

So far, only a couple of studies have been published that investigated the effects of PDE2 inhibition in behavioral models. To our knowledge, BAY 60-7550 is the only selective PDE2-I which has been tested in animal models of cognition (Boess et al. 2004; Domek-Lopacinska and Strosznajder 2008; Rutten et al. 2007b). It has been shown that BAY 607550 improved memory acquisition and consolidation in the object recognition task in both rats and mice and consolidation in the social recognition task in rats (Boess et al. 2004; Domek-Lopacinska and Strosznajder 2008; Rutten et al. 2007b). In addition, this PDE2-I improved acquisition and consolidation in the object recognition task in age-impaired rats (Domek-Lopacinska and Strosznajder 2008).

Furthermore, BAY 60-7550 reversed the MK-801-induced working memory deficit in the T-maze in mice (Boess et al. 2004). A more detailed overview of these studies is provided in Table 3.

\section{PDE4}

The next section provides a general summary of the available literature on PDE4-Is and cognition. A more detailed overview is provided in Table 4.
It has been shown in several studies that acute as well as subchronic administration of the PDE4-I rolipram improved memory consolidation in unimpaired rats in the object recognition task (Rutten et al. 2007a, b, 2008c). In addition, memory deficits caused by scopolamine or acute tryptophan depletion were reversed by rolipram in this task (Rutten et al. 2007a, 2006). Several spatial memory tasks (e.g., water escape task and radial arm maze) showed that PDE4-Is did not only improve spatial memory in unimpaired rats and mice (Bach et al. 1999; Huang et al. 2007), but also in rats of which spatial memory was impaired by age or microsphere embolism-induced cerebral ischemia (Nagakura et al. 2002). An impairment of spatial reference memory in the radial arm maze caused by scopolamine, MK-801, or MAPK/ERK kinase (MEK) inhibition was also reversed by various PDE4-Is (Egawa et al. 1997; Zhang et al. 2000, 2004, 2005; Zhang and O’Donnell 2000).

In addition, various studies investigated the effects of PDE4-Is on passive avoidance learning and PDE4-Is reversed impairments caused by scopolamine, MK-801, anisomycin, and MEK inhibition in this task (Egawa et al. 1997; Ghelardini et al. 2002; Imanishi et al. 1997; Randt et al. 1982; Zhang et al. 2005, 2004; Zhang and O'Donnell 2000). Furthermore, it was shown that acute as well as chronic treatment of rolipram improved the performance of unimpaired rats and mice in contextual fear conditioning (Barad et al. 1998; Comery et al. 2005; Monti et al. 2006).

The effects of PDE4-Is on working memory in rats have been studied in various deficit models. It was shown that working memory deficits caused by scopolamine, MK-801, cerebral ischemia, or electroconvulsive shocks (ECS) were reversed by the administration of PDE4-Is in the radial arm maze and the three-panel runway task (Egawa et al. 1997; 
Table 3 Overview of effects of PDE2-Is on cognition

\begin{tabular}{|c|c|c|c|c|}
\hline $\begin{array}{l}\text { Task (cognitive process, } \\
\text { area involved) }\end{array}$ & Model (species) & Treatment & Results & Reference \\
\hline \multirow[t]{4}{*}{$\begin{array}{l}\text { Object recognition task } \\
\text { (object memory, } \\
\text { hippocampus and } \\
\text { rhinal cortex) }\end{array}$} & Unimpaired (rat) & $\begin{array}{l}\text { BAY } 60-7550(3 \mathrm{mg} / \mathrm{kg}, \mathrm{p} . \mathrm{o} .) \\
\text { immediately after, } 1 \mathrm{~h}, 3 \mathrm{~h} \text { or } \\
6 \mathrm{~h} \text { after first trial }(24 \mathrm{~h} \text { interval } \\
\mathrm{T} 1-\mathrm{T} 2)\end{array}$ & $\begin{array}{l}\text { BAY } 60-7550(3 \mathrm{mg} / \mathrm{kg}, \\
\text { immediately after T1 or } \\
3 \mathrm{~h} \text { after T1) improved } \\
\text { memory consolidation }\end{array}$ & Rutten et al. (2007b) \\
\hline & Unimpaired (rat) & $\begin{array}{l}\text { BAY } 60-7550(0.3,1 \text { or } \\
3 \mathrm{mg} / \mathrm{kg} \text {, p.o.) immediately after } \\
\text { first trial }(24 \mathrm{~h} \text { interval } \mathrm{T} 1-\mathrm{T} 2)\end{array}$ & $\begin{array}{l}\text { BAY } 60-7550(1 \text { or } 3 \mathrm{mg} / \mathrm{kg} \text {, } \\
\text { immediately after } \mathrm{T} 1) \\
\text { improved memory } \\
\text { consolidation }\end{array}$ & Boess et al. (2004) \\
\hline & $\begin{array}{l}\text { Impaired by age, } 3 \text {, } \\
12 \text { and } 24 \text { months } \\
\text { old (rat) }\end{array}$ & $\begin{array}{l}\text { BAY } 60-7550(0.3 \mathrm{mg} / \mathrm{kg} \text {, s.c. }) \\
1 \mathrm{~h} \text { before first trial or } \\
\text { immediately after first trial } \\
(2 \mathrm{~h} \text { interval } \mathrm{T} 1-\mathrm{T} 2)\end{array}$ & $\begin{array}{l}\text { BAY } 60-75501 \mathrm{~h} \text { before } \mathrm{T} 1 \\
\text { improved acquisition in all } \\
\text { age groups. In addition, it } \\
\text { improved consolidation in } \\
\text { animals of } 3 \text { and } 12 \text { months } \\
\text { when given immediately } \\
\text { after T1 }\end{array}$ & $\begin{array}{l}\text { Domek-Lopacinska } \\
\text { and Strosznajder (2008) }\end{array}$ \\
\hline & Unimpaired (mouse) & $\begin{array}{l}\text { BAY } 60-7550(0.3,1 \text { or } \\
3 \mathrm{mg} / \mathrm{kg} \text {, p.o. }) \text { immediately after } \\
\text { first trial }(24 \mathrm{~h} \text { interval } \mathrm{T} 1-\mathrm{T} 2)\end{array}$ & $\begin{array}{l}\text { BAY } 60-7550(0.3 \text { or } 1 \mathrm{mg} / \mathrm{kg} \text {, } \\
\text { immediately after } \mathrm{T} 1) \\
\text { improved memory } \\
\text { consolidation }\end{array}$ & Boess et al. (2004) \\
\hline $\begin{array}{l}\text { Social recognition } \\
\text { (social memory, } \\
\text { hippocampus } \\
\text { and amygdala) }\end{array}$ & Unimpaired (rat) & $\begin{array}{c}\text { BAY } 60-7550(0.3,0.6,1,2,3 \text { or } \\
6 \mathrm{mg} / \mathrm{kg} \text {, p.o.) immediately after } \\
\text { first trial }(24 \mathrm{~h} \text { interval } \mathrm{T} 1-\mathrm{T} 2)\end{array}$ & $\begin{array}{l}\text { BAY } 60-7550(1,2,3 \text {, or } \\
6 \mathrm{mg} / \mathrm{kg} \text {, immediately after } \\
\text { T1) improved memory } \\
\text { consolidation }\end{array}$ & Boess et al. (2004) \\
\hline $\begin{array}{l}\text { T-maze (working } \\
\text { memory, } \\
\text { hippocampus) }\end{array}$ & $\begin{array}{l}\text { Impaired by MK- } \\
801,0.125 \mathrm{mg} / \mathrm{kg} \text {, } \\
\text { i.p., } 30 \mathrm{~min} \text { before } \\
\text { test session } \\
\text { (mouse) }\end{array}$ & $\begin{array}{l}\text { BAY } 60-7550(0.3,1, \text { or } \\
3 \mathrm{mg} / \mathrm{kg}, \text { p.o. }) 30 \mathrm{~min} \text { before } \\
\text { test session }\end{array}$ & $\begin{array}{l}\text { BAY } 60-7550(3 \mathrm{mg} / \mathrm{kg}) \\
\text { reversed MK- } 801 \text { induced } \\
\text { deficit }\end{array}$ & Boess et al. (2004) \\
\hline
\end{tabular}

$T 1$ trial 1, T2 trial 2, p.o. per os, i.p. intraperitoneal

Imanishi et al. 1997; Zhang et al. 2000, 2005, 2004). Of note, the effects of rolipram on spatial working memory are twofold; on one hand, rolipram tended to improve working memory in young rhesus monkeys in a delayed responding task (Ramos et al. 2003). However, on the other hand, rolipram had a negative effect on working memory in aged monkeys in this task (Ramos et al. 2003, 2006).

The effects of rolipram on information processing have been studied in several behavioral setups in the prepulse inhibition and startle response task. Rolipram did not only facilitate information processing in unimpaired mice and zebrafish, but also reversed deficits caused by D-amphetamine in mice (Best et al. 2008; Kanes et al. 2007). In contrast, PDE4-I RO-20-1724 did not reverse the prepulse inhibition deficit caused by D-amphetamine (Halene and Siegel 2008). In another model of information processing, sensory gating, this PDE-I increased the amplitudes of P20 and N40 in the CA3 area during the first stimulus and reversed the N40 deficit in the first click caused by D-amphetamine (Halene and Siegel 2008). Additionally, executive functioning was improved in an object retrieval task in cynomolgus macaques after the administration of rolipram (Rutten et al. 2008a). In this task, monkeys try to retrieve a food reward from a transparent box with one open side that alternates between trials. This is a prefrontal cortical-mediated task likely to capture attention and response inhibition, and rolipram treatment significantly dose-dependently enhanced performance, as measured by an increased percentage of correct first reaches.

Besides deficit models based on pharmacological or surgical interventions, the use of transgenic animals, i.e., isoform-specific knockout models of PDE4B or PDE4D, have been recently introduced to study the role of PDE4 in the central nervous system (CNS). It was shown that PDE4B knockout (KO) in mice had no effect on spatial memory performance in the water escape task and the passive avoidance task (Siuciak et al. 2008a). Furthermore, these mice showed an impairment in information processing in the prepulse inhibition task (Siuciak et al. 2008a), although they performed similar to wild-type animals on conditioned avoidance responding (Siuciak et al. 2007). A recent study 
Table 4 Overview of effects of PDE4-Is on cognition

\begin{tabular}{|c|c|c|c|c|}
\hline $\begin{array}{l}\text { Task (cognitive process, } \\
\text { area involved) }\end{array}$ & Model (species) & Treatment & Results & Reference \\
\hline \multirow[t]{2}{*}{$\begin{array}{l}\text { Water escape task } \\
\text { (spatial memory, } \\
\text { hippocampus) }\end{array}$} & $\begin{array}{l}\text { Impaired by microsphere } \\
\text { embolism-induced cerebral } \\
\text { ischemia (rat) }\end{array}$ & $\begin{array}{l}\text { Rolipram ( } 3 \mathrm{mg} / \mathrm{kg} \text {, i.p.) } \\
10 \text { days, after embolism }\end{array}$ & $\begin{array}{l}\text { Rolipram attenuates } \\
\text { acquisition deficit measured } \\
\text { at days } 7-9\end{array}$ & Nagakura et al. (2002) \\
\hline & $\begin{array}{l}\text { Impaired by PDE4B KO } \\
\text { (mouse) }\end{array}$ & - & No effect & Siuciak et al. (2008a) \\
\hline $\begin{array}{l}\text { Delayed matching to } \\
\text { position water maze } \\
\text { (spatial memory, } \\
\text { hippocampus) }\end{array}$ & Unimpaired (rat) & $\begin{array}{l}\mathrm{L}-454,560(0,0.1,0.3 \text {, or } \\
1 \mathrm{mg} / \mathrm{kg}, \text { p.o. }) 30 \mathrm{~min} \\
\text { before testing }\end{array}$ & $\begin{array}{l}\mathrm{L}-454,560(0.3 \text { and } 1 \mathrm{mg} / \mathrm{kg}) \\
\text { improved performance }\end{array}$ & Huang et al. (2007) \\
\hline \multirow[t]{2}{*}{$\begin{array}{l}\text { Radial arm water maze } \\
\text { (spatial memory, } \\
\text { hippocampus) }\end{array}$} & $\begin{array}{l}\text { Impaired by APP-PS1 } \\
\text { Alzheimer KO (mouse) }\end{array}$ & $\begin{array}{l}\text { Rolipram }(0.03 \mathrm{mg} / \mathrm{kg} \text {, s.c. }) \\
\text { for } 3 \text { weeks }\end{array}$ & $\begin{array}{l}\text { Improvement when tested at } \\
2 \text { months after } 3 \text {-week } \\
\text { treatment }\end{array}$ & Gong et al. (2004) \\
\hline & $\begin{array}{l}\text { Impaired by PS1/PDAPP } \\
\text { KO (mouse) }\end{array}$ & $\begin{array}{l}\text { Rolipram }(0.03 \mathrm{mg} / \mathrm{kg}, \mathrm{s.c} .) \\
\text { once a day for } 2 \text { weeks } \\
\text { before testing }\end{array}$ & $\begin{array}{l}\text { Rolipram improved working } \\
\text { memory }\end{array}$ & Costa et al. (2007) \\
\hline $\begin{array}{l}\text { Barnes circular maze } \\
\text { (spatial memory, } \\
\text { hippocampus) }\end{array}$ & $\begin{array}{l}\text { Impaired by age, } 18 \text { months } \\
\text { old (mouse) }\end{array}$ & $\begin{array}{l}\text { Rolipram }(0.016 \mathrm{mg} / \mathrm{kg} \text {, i.p. }) \\
40 \mathrm{~min} \text { before training }\end{array}$ & $\begin{array}{l}\text { More mice acquire the task } \\
\text { and number of errors is } \\
\text { reduced }\end{array}$ & Bach et al. (1999) \\
\hline \multirow[t]{5}{*}{$\begin{array}{l}\text { Radial arm maze } \\
\text { (working and reference } \\
\text { memory, hippocampus) }\end{array}$} & $\begin{array}{l}\text { Impaired by scopolamine } \\
0.5 / 1.0 \mathrm{mg} / \mathrm{kg} \text {, i.p., } 30 \mathrm{~min} \\
\text { before test (rat) }\end{array}$ & $\begin{array}{l}\text { Rolipram }(0.01-1 \mathrm{mg} / \mathrm{kg} \text {, } \\
\text { i.p.) } 45 \mathrm{~min} \text { before test }\end{array}$ & $\begin{array}{l}\text { MED: } 0.1 \text { (working } \\
\text { memory) and }>0.1 \mathrm{mg} / \mathrm{kg} \\
\text { (reference memory) }\end{array}$ & $\begin{array}{l}\text { Zhang and O'Donnell } \\
\text { (2000) }\end{array}$ \\
\hline & $\begin{array}{l}\text { Impaired by scopolamine, } \\
0.5 \mathrm{mg} / \mathrm{kg} \text {, i.p., } 30 \mathrm{~min} \\
\text { before test (rat) }\end{array}$ & $\begin{array}{l}\text { Given } 30 \mathrm{~min} \text { before test } \\
( \pm) \text {-rolipram } 0.01-1 \mathrm{mg} / \mathrm{kg} \text {, } \\
\text { p.o.; (-)-rolipram } 0.005- \\
1 \mathrm{mg} / \mathrm{kg}, \text { p.o.; (+)-rolipram } \\
0.1-50 \mathrm{mg} / \mathrm{kg} \text {, p.o. }\end{array}$ & $\begin{array}{l}\text { MED (working memory): } \\
( \pm) \text {-rolipram } 0.02- \\
0.2 \mathrm{mg} / \mathrm{kg},(-) \text {-rolipram } \\
0.01-0.02 \text { and } \\
0.2 / 0.5 \mathrm{mg} / \mathrm{kg} \text { (bi phasic), } \\
(+)-\text { rolipram } 20 / 50 \mathrm{mg} / \mathrm{kg}\end{array}$ & Egawa et al. (1997) \\
\hline & $\begin{array}{l}\text { Impaired by MK- } \\
801,0.1 \mathrm{mg} / \mathrm{kg} \text {, i.p., } 60 \mathrm{~min} \\
\text { before test (rat) }\end{array}$ & $\begin{array}{l}\text { Rolipram }(0.01-0.1 \mathrm{mg} / \mathrm{kg} \text {, } \\
\text { i.p.) } 30 \mathrm{~min} \text { before test }\end{array}$ & $\begin{array}{l}\text { MED: } 0.05 \text { (working } \\
\text { memory) and } 0.1 \mathrm{mg} / \mathrm{kg} \\
\text { (reference memory) }\end{array}$ & Zhang et al. (2000) \\
\hline & $\begin{array}{l}\text { Impaired by MK- } 801 \text {, } \\
0.1 \mathrm{mg} / \mathrm{kg} \text {, i.p., } 60 \mathrm{~min} \\
\text { before testing (rat) }\end{array}$ & $\begin{array}{l}\text { Rolipram }(0.1 \mathrm{mg} / \mathrm{kg} \text {, i.p. }) \\
\text { MEM } 1018 \text { or MEM } 1091 \\
\text { (0.1-2.5 mg/kg, i.p.) } \\
45 \text { min before test }\end{array}$ & $\begin{array}{l}\text { MED: } 0.1 \mathrm{mg} / \mathrm{kg} \text { rolipram } \\
\text { working memory, MED: } \\
2.5 \mathrm{mg} / \mathrm{kg} \text { MEM } 1018 \\
\text { working and reference } \\
\text { memory MED: } 2.5 \mathrm{mg} / \mathrm{kg} \\
\text { MEM } 1091 \text { on reference } \\
\text { memory }\end{array}$ & Zhang et al. (2005) \\
\hline & $\begin{array}{l}\text { Impaired by MEK inhibitor } \\
\text { UO126, } 8 \mu \mathrm{g} / \text { rat into } \\
\text { hippocampus, given twice: } \\
60 \text { and } 30 \text { min before test } \\
\text { (rat) }\end{array}$ & $\begin{array}{l}\text { Rolipram }(0.05,0.1, \mathrm{mg} / \mathrm{kg} \text {, } \\
\text { i.p.) } 30 \mathrm{~min} \text { before test }\end{array}$ & $\begin{array}{l}\text { MED: } 0.1 \mathrm{mg} / \mathrm{kg} \text { (reference } \\
\text { memory) }\end{array}$ & Zhang et al. (2004) \\
\hline \multirow[t]{3}{*}{$\begin{array}{l}\text { Passive avoidance } \\
\text { (inhibitory avoidance } \\
\text { learning, hippocampus } \\
\text { and amygdala) }\end{array}$} & $\begin{array}{l}\text { Impaired by (1) protein } \\
\text { synthesis inhibitor } \\
\text { anisomycin, } 150 \mathrm{mg} / \mathrm{kg} \text {, } \\
\text { s.c., } 30 \mathrm{~min} \text { before training, } \\
\text { (2) low baseline (mouse) }\end{array}$ & $\begin{array}{l}\text { Rolipram }(3 \text { or } 10 \mathrm{mg} / \mathrm{kg} \text {, } \\
\text { i.p., immediately after } \\
\text { training or } 3 \mathrm{~h} \text { after training }\end{array}$ & $\begin{array}{l}\text { MED } 10 \mathrm{mg} / \mathrm{kg} \text {, given } \\
\text { immediately after training } \\
(1+2)\end{array}$ & Randt et al. (1982) \\
\hline & $\begin{array}{l}\text { Impaired by scopolamine, } \\
1 \mathrm{mg} / \mathrm{kg} \text {, i.p., } 30 \mathrm{~min} \text { before } \\
\text { acquisition (mouse) }\end{array}$ & $\begin{array}{l}\text { Rolipram (1-30 mg/kg, i.p.) } \\
30 \text { min before acquisition }\end{array}$ & MED: $10 \mathrm{mg} / \mathrm{kg}$ & Imanishi et al. (1997) \\
\hline & $\begin{array}{l}\text { Impaired by scopolamine, } \\
1.5 \mathrm{mg} / \mathrm{kg} \text {, i.p., } \\
\text { immediately after training } \\
\text { (mouse) }\end{array}$ & $\begin{array}{l}\text { Rolipram }(10 \text { or } 30 \mathrm{mg} / \mathrm{kg}, \\
\text { p.o.) } 30 \mathrm{~min} \text { before training }\end{array}$ & MED: $30 \mathrm{mg} / \mathrm{kg}$ & Ghelardini et al. (2002) \\
\hline
\end{tabular}


Table 4 (continued)

\begin{tabular}{llll}
\hline $\begin{array}{l}\text { Task (cognitive process, } \\
\text { area involved) }\end{array}$ & Model (species) & Treatment & Refults
\end{tabular}

Impaired by scopolamine, $3 \mathrm{mg} / \mathrm{kg}$, i.p., $30 \mathrm{~min}$ before retention test (rat)

Impaired by MK-801

$0.1 \mathrm{mg} / \mathrm{kg}$, i.p., $60 \mathrm{~min}$

before test (rat)

Impaired by MK-801,

$0.1 \mathrm{mg} / \mathrm{kg}$, i.p., $60 \mathrm{~min}$

before testing (rat)

Impaired by MEK inhibitor

UO126, $8 \mu \mathrm{g} / \mathrm{rat}$ into

hippocampus, given twice:

(rat)

Impaired by PDE4B KO

(mouse)

Three-panel runway task Impaired by scopolamine,

(working memory,

hippocampus and

prefrontal cortex)

$0.56 \mathrm{mg} / \mathrm{kg}$, i.p., $15 \mathrm{~min}$

before first trial (rat)

Impaired by cerebral

ischemia by four-vessel

occlusion (rat)

Impaired by ECS immediately after training (rat)

Impaired by (1) protein

synthesis inhibitor

anisomycin, $150 \mathrm{mg} / \mathrm{kg}$,

s.c., $30 \mathrm{~min}$ before training,

(2) low baseline (mouse)

Contextual fear

Unimpaired (mouse)

conditioning (learning,

hippocampus and Unimpaired (rat)

amygdala)

Object recognition task

(object memory,

hippocampus and rhinal

cortex)

Impaired by TG2576 KO

Alzheimer mice (mouse)

Impaired by APP-PS KO

Alzheimer mice (mouse)

Impaired by PDE4D KO

(mouse)

Unimpaired young (rat)
60 and 30 min before test

Given 60 min before

retention test. $( \pm)$-rolipram

0.01-0.1 mg/kg, p.o.; (-)-

rolipram $0.005-0.02 \mathrm{mg} / \mathrm{kg}$,

p.o.; (+)-rolipram $0.3-$

$10 \mathrm{mg} / \mathrm{kg}$, p.o.

Rolipram (0.1 mg/kg, i.p.) $\quad$ MED: $\leq 0.1 \mathrm{mg} / \mathrm{kg}$

$30 \mathrm{~min}$ before test

Rolipram (0.1 mg/kg, i.p.),

MEM 1018 or MEM 1091

(0.1-2.5 mg/kg, i.p.)

$45 \mathrm{~min}$ before test

Rolipram (0.1, mg/kg, i.p.)

$30 \mathrm{~min}$ before test or

$30 \mu \mathrm{g} / \mathrm{rat}$ into

hippocampus, $20 \mathrm{~min}$

before test

$-$

Rolipram (0.032 or

$0.1 \mathrm{mg} / \mathrm{kg}$, i.p.) $30 \mathrm{~min}$

before first trial

Rolipram (0.032 or

$0.1 \mathrm{mg} / \mathrm{kg}$, i.p.) $30 \mathrm{~min}$

before first trial

(immediately after

reperfusion)

Rolipram $(0.1$ or $0.32 \mathrm{mg} / \mathrm{kg}$,

i.p.) just before ECS

Rolipram (3 or $10 \mathrm{mg} / \mathrm{kg}$, i.p., immediately after

training or $3 \mathrm{~h}$ after training

Rolipram (0.03 mg/kg, s.c.)

$30 \mathrm{~min}$ before training

Rolipram $0.5 \mathrm{mg} / \mathrm{kg} /$ day for

7 days chronic delivery by osmotic minipumps

at $10 \mathrm{mg} / \mathrm{kg}$ latency

No effect

decrease errors

decrease errors

decrease errors

$(1+2)$

after training

Improved memory

fear

Rolipram (0.1 mg/kg, i.p.)

30 min prior to training

Rolipram $0.1 \mu \mathrm{M} / \mathrm{kg}$ for

3 weeks

wild-type

treatment and cued fear

Rolipram (0.01, 0.03 or
MED: ( \pm )-rolipram 0.02-

$0.1 \mathrm{mg} / \mathrm{kg},(-)$-rolipram

0.01-0.02 mg/kg, (+)-

rolipram $2 \mathrm{mg} / \mathrm{kg}$; no effect

MED: rolipram $0.1 \mathrm{mg} / \mathrm{kg}$, MEM1018 0.1-2.5 mg/kg, and MEM $10910.5-$

$2.5 \mathrm{mg} / \mathrm{kg}$ on reversal

Reversal retention deficit

$48 \mathrm{~h}$ post training

Egawa et al. (1997)

Zhang et al. (2000)

Zhang et al. (2005)

Zhang et al. (2004)

Siuciak et al. (2008a)

MED: $0.1 \mathrm{mg} / \mathrm{kg}$ for

Imanishi et al. (1997)

MED: $0.1 \mathrm{mg} / \mathrm{kg}$ for

Imanishi et al. (1997)

MED: $0.32 \mathrm{mg} / \mathrm{kg}$ for

MED $10 \mathrm{mg} / \mathrm{kg}$, given

immediately after training

Improved retention $24 \mathrm{~h}$

consolidation and slower

extinction of conditioned

Improvement in mutants and

Improvement when tested

2 months following 3-week

Impairment LTM for context $0.1 \mathrm{mg} / \mathrm{kg}$, i.p.) given:

(1) 30 min before training,

(2) directly after training,

(3) $3 \mathrm{~h}$ after training
Rolipram (0.03 mg/kg 3 h

after T1) improved memory

consolidation in ORT
Barad et al. (1998)

Imanishi et al. (1997)

Randt et al. (1982)

Monti et al. (2006)

Comery et al. (2005)

Gong et al. (2004)

Rutten et al. (2008b)

Rutten et al. (2006) 
Table 4 (continued)

\begin{tabular}{|c|c|c|c|c|}
\hline $\begin{array}{l}\text { Task (cognitive process, } \\
\text { area involved) }\end{array}$ & Model (species) & Treatment & Results & Reference \\
\hline & Unimpaired young (rat) & $\begin{array}{l}\text { Rolipram (0.03 mg/kg, i.p.) } \\
\text { given: (1) directly after } \\
\text { training, (2) } 1 \mathrm{~h} \text { after } \\
\text { training, (3) } 3 \mathrm{~h} \text { after } \\
\text { training, (4) } 6 \mathrm{~h} \text { after } \\
\text { training }\end{array}$ & $\begin{array}{l}\text { Rolipram }(0.03 \mathrm{mg} / \mathrm{kg} 3 \mathrm{~h} \\
\text { after T1) improved memory } \\
\text { consolidation in ORT }\end{array}$ & Rutten et al. (2007b) \\
\hline & $\begin{array}{l}\text { Impaired by scopolamine, } \\
0.1 \mathrm{mg} / \mathrm{kg} \text {, i.p., } 30 \mathrm{~min} \\
\text { before training (rat) }\end{array}$ & $\begin{array}{l}\text { Rolipram }(0.03,0.1 \text { or } \\
0.3 \mathrm{mg} / \mathrm{kg} \text {, i.p. }) 30 \mathrm{~min} \\
\text { before training }\end{array}$ & $\begin{array}{l}\text { Rolipram }(0.1 \mathrm{mg} / \mathrm{kg}) \\
\text { reversed the scopolamine- } \\
\text { induced STM deficit }\end{array}$ & Rutten et al. (2006) \\
\hline & $\begin{array}{l}\text { Impaired by acute tryptophan } \\
\text { depletion, } 3 \mathrm{~h} \text { before } \\
\text { training (rat) }\end{array}$ & $\begin{array}{l}\text { Rolipram }(0.01,0.03 \text { or } \\
0.1 \mathrm{mg} / \mathrm{kg} \text {, i.p. }) 30 \mathrm{~min} \\
\text { before training }\end{array}$ & $\begin{array}{l}\text { Rolipram }(0.1 \mathrm{mg} / \mathrm{kg}) \\
\text { reversed ATD induced STM } \\
\text { deficit }\end{array}$ & Rutten et al. (2007a) \\
\hline & Unimpaired (rat) & $\begin{array}{l}\text { Subchronic treatment of } \\
\text { rolipram }(0.5 \mathrm{mg} / \mathrm{kg} \text {, p.o. }) \\
\text { for } 5 \text { days. Testing before, } \\
\text { during (day } 2-3) \text { and after } \\
\text { treatment }(\mathrm{T} 1-\mathrm{T} 224 \mathrm{~h})\end{array}$ & $\begin{array}{l}\text { Subchronic rolipram } \\
\text { treatment improved object } \\
\text { recognition memory. } \\
\text { Timing of final dose did not } \\
\text { affect performance }\end{array}$ & Rutten et al. (2008c) \\
\hline & $\begin{array}{l}\text { Impaired by heterozygous } \\
\text { CBP mutation (mouse) }\end{array}$ & $\begin{array}{l}\text { Rolipram }(0.1 \mathrm{mg} / \mathrm{kg} \text {, i.p. }) \text { or } \\
\text { HT0712 }(0.001-0.5 \mathrm{mg} / \mathrm{kg} \text {, } \\
\text { i.p. } 20 \mathrm{~min} \text { before training }\end{array}$ & $\begin{array}{l}\text { MED: } 0.1 \mathrm{mg} / \mathrm{kg} \text { for both } \\
\text { drugs. Improved object } \\
\text { recognition at } 24 \mathrm{~h}\end{array}$ & $\begin{array}{l}\text { Bourtchouladze et al. } \\
\text { (2003) }\end{array}$ \\
\hline \multirow[t]{2}{*}{$\begin{array}{l}\text { Delayed responding } \\
\text { (spatial working } \\
\text { memory, prefrontal } \\
\text { cortex) }\end{array}$} & $\begin{array}{l}\text { Unimpaired young and aged- } \\
\text { impaired (rhesus monkey) }\end{array}$ & $\begin{array}{l}\text { Rolipram }(0.01-100 \mu \mathrm{g} / \mathrm{kg} \text {, } \\
\text { i.m.) } 1 \mathrm{~h} \text { before testing }\end{array}$ & $\begin{array}{l}\text { At } 0.1 \mu \mathrm{g} / \mathrm{kg} \text {, trend for } \\
\text { improvement in young } \\
\text { subjects. Aged subjects } \\
\text { impaired by } 10 \mu \mathrm{g} / \mathrm{kg}\end{array}$ & Ramos et al. (2003) \\
\hline & $\begin{array}{l}\text { Impaired by age (rhesus } \\
\text { monkey) }\end{array}$ & $\begin{array}{l}\text { Rolipram }(0,0.001- \\
0.05 \mu \mathrm{g} / \mathrm{kg}, \mathrm{i} . \mathrm{m} .) 2 \mathrm{~h} \text { before } \\
\text { testing and guanfacine } \\
(0,0.0001-0.01 \mathrm{mg} / \mathrm{kg}, \mathrm{i} . \mathrm{m} . \\
(\text { one animal } 0.5 \mathrm{mg} / \mathrm{kg}))\end{array}$ & $\begin{array}{l}\text { Rolipram alone no effect. } \\
\text { Rolipram reversed } \\
\text { beneficial effect of } \\
\text { guanfacine on working } \\
\text { memory }\end{array}$ & Ramos et al. (2006) \\
\hline $\begin{array}{l}\text { Object retrieval } \\
\text { (executive functioning } \\
\text { and response inhibition, } \\
\text { prefrontal cortex) }\end{array}$ & $\begin{array}{l}\text { Unimpaired (cynomolgus } \\
\text { macaque) }\end{array}$ & $\begin{array}{l}\text { Rolipram }(0.003,0.01, \text { or } \\
0.03 \mathrm{mg} / \mathrm{kg} \text {, i.m. } 30 \mathrm{~min} \\
\text { before testing }\end{array}$ & $\begin{array}{l}\text { Rolipram }(0.01,0.33 \mathrm{mg} / \mathrm{kg}) \\
\text { improved object retrieval } \\
\text { performance }\end{array}$ & Rutten et al. (2008a) \\
\hline \multirow{4}{*}{$\begin{array}{l}\text { Prepulse inhibition } \\
\text { (information } \\
\text { processing, frontal } \\
\text { cortex) }\end{array}$} & Unimpaired (mouse) & $\begin{array}{l}\text { Rolipram }(0.1,0.66,1 \text { or } \\
10 \mathrm{mg} / \mathrm{kg} \text {, i.p. }) 15 \mathrm{~min} \\
\text { before testing }\end{array}$ & $\begin{array}{l}\text { Rolipram }(0.66,1,10 \mathrm{mg} / \mathrm{kg}) \\
\text { increased PPI and decreased } \\
\text { startle response }\end{array}$ & Kanes et al. (2007) \\
\hline & $\begin{array}{l}\text { Impaired by D-amphetamine, } \\
10 \mathrm{mg} / \mathrm{kg} \text {, i.p., } 15 \mathrm{~min} \\
\text { before testing (mouse) }\end{array}$ & $\begin{array}{l}\text { D-amphetamine }(10 \mathrm{mg} / \mathrm{kg} \text {, } \\
\text { i.p.) and rolipram } \\
\text { (0.66 } \mathrm{mg} / \mathrm{kg} \text {, i.p.) } 15 \mathrm{~min} \\
\text { before testing }\end{array}$ & $\begin{array}{l}\text { Rolipram attenuated the PPI } \\
\text { deficit caused by } \\
\text { d-amphetamine, but had no } \\
\text { effect on startle response }\end{array}$ & Kanes et al. (2007) \\
\hline & $\begin{array}{l}\text { Impaired by PDE4B KO } \\
\text { (mouse) }\end{array}$ & - & $\begin{array}{l}\text { Increased startle response } \\
\text { and decreased PPI } \\
\text { (independent of startle } \\
\text { response) }\end{array}$ & Siuciak et al. (2008a) \\
\hline & $\begin{array}{l}\text { Impaired by D-amphetamine, } \\
5 \mathrm{mg} / \mathrm{kg} \text { (mouse) }\end{array}$ & $\begin{array}{l}\text { RO-20-1724 }(0.25,2.5 \text {, or } \\
4 \mathrm{mg} / \mathrm{kg}, \text { s.c.) or rolipram } \\
\text { (mg/kg, s.c.), } 5 \text { min before } \\
\text { testing }\end{array}$ & $\begin{array}{l}\text { RO-20-1724 did not reverse } \\
\text { PPI deficit caused by } \\
\text { d-amphetamine }\end{array}$ & $\begin{array}{l}\text { Halene and Siegel } \\
\text { (2008) }\end{array}$ \\
\hline $\begin{array}{l}\text { Startle response } \\
\text { (nonassociative } \\
\text { learning) }\end{array}$ & Unimpaired (zebrafish) & Rolipram $(3,10$, or $30 \mu \mathrm{M})$ & $\begin{array}{l}\text { Rolipram }(3 \mu \mathrm{M}) \text { enhanced } \\
\text { startle response }\end{array}$ & Best et al. (2008) \\
\hline Acquisition of & Impaired by PDE4B KO & - & No effect & Siuciak et al. (2007) \\
\hline
\end{tabular}

conditioned avoidance

(mouse)

responding (learning,

hippocampus) 
Table 4 (continued)

\begin{tabular}{|c|c|c|c|c|}
\hline $\begin{array}{l}\text { Task (cognitive process, } \\
\text { area involved) }\end{array}$ & Model (species) & Treatment & Results & Reference \\
\hline \multirow[t]{2}{*}{$\begin{array}{l}\text { Auditory event-related } \\
\text { potentials (information } \\
\text { processing, frontal } \\
\text { cortex) }\end{array}$} & Unimpaired (mouse) & $\begin{array}{l}\text { RO-20-1724 (0.1, 0.25, 0.5, } \\
1,2.5 \mathrm{mg} / \mathrm{kg}, \mathrm{s.c} .), 5 \mathrm{~min} \\
\text { before testing }\end{array}$ & $\begin{array}{l}\text { First click: RO-20-1724 } \\
\text { increased amplitude of P20 } \\
\text { (at a dose of } 0.25,0.5, \\
1 \mathrm{mg} / \mathrm{kg} \text { ) and of N40 at a } \\
\text { dose of }(0.25,0.5, \\
2.5 \mathrm{mg} / \mathrm{kg} \text { ) in CA3 area. } \\
\text { No effects on second click }\end{array}$ & $\begin{array}{l}\text { Halene and Siegel } \\
(2008)\end{array}$ \\
\hline & $\begin{array}{l}\text { Impaired by D-amphetamine, } \\
0.5 \mathrm{mg} / \mathrm{kg} \text { (mouse) }\end{array}$ & $\begin{array}{l}\text { RO- } 20-1724(0.25 \mathrm{mg} / \mathrm{kg} \\
\text { s.c. }), 5 \text { min before testing }\end{array}$ & $\begin{array}{l}\text { First click: P20 no effect. } \\
\text { N40 RO-20-1734 reversed } \\
\text { deficit caused by } \\
\text { d-amphetamine in CA3 } \\
\text { area. No effects on second } \\
\text { click }\end{array}$ & $\begin{array}{l}\text { Halene and Siegel } \\
\text { (2008) }\end{array}$ \\
\hline
\end{tabular}

This table is an adapted and updated version of the overview (Table 3) in Blokland et al. (2006)

$K O$ knockout, i.m. intramuscular, i.p. intraperitoneal, p.o. per os, s.c. subcutaneous, MEK MAPK/ERK kinase, T1 trial $1, T 2$ trial $2, E C S$ electroconvulsive shocks, $A T D$ acute tryptophan depletion, $O R T$ object recognition task, $M E D$ minimum effective dose

showed more controversial data demonstrating enhanced LTP but impaired fear conditioning in PDE4D knockout mice (Rutten et al. 2008b).

In addition, a variety of transgenic mice models was used in combination with the administration of PDE4-Is. It has been shown that acute as well as chronic treatment of PDE4Is improved long-term memory (LTM) functioning in a Rubenstein-Taybi syndrome and two Alzheimer's disease $\mathrm{KO}$ mouse models for cognitive impairment in the fear conditioning and object recognition task (Bourtchouladze et al. 2003; Comery et al. 2005; Gong et al. 2004). Also, PDE4-I rolipram improved working memory and spatial memory in a transgenic model of Alzheimer's disease, i.e., PS1/PDAPP KO mice in the radial arm water maze (Costa et al. 2007; Gong et al. 2004).

To our knowledge, no studies have been published in which the effects of PDE4-Is on cognition in humans are described. However, PDE4-I MK 0952 is now entering phase 2 clinical trials for cognition enhancement (Merck and Co. 2006).

\section{PDE5}

Prickaerts et al. (1997) were the first to describe memoryenhancing effects of PDE5 inhibition using the PDE5-I zaprinast. However, zaprinast is not selective for PDE5, as it also inhibits PDE1, 9, 10, and 11 (Bender and Beavo 2006). Recently, more highly selective PDE5 inhibitors have been developed mainly for the treatment of erection disorder, e.g., sildenafil (Viagra), vardenafil (Levitra), and tadalafil (Cialis) (Setter et al. 2005). The next section will give a general summary of the available literature on PDE5-Is and cognition; a more detailed overview is provided in Table 5.
So far, several studies have shown positive effects of selective PDE5-Is on memory performance in the object recognition task in adult rats; zaprinast (Domek-Lopacinska and Strosznajder 2008; Prickaerts et al. 1997), sildenafil (Prickaerts et al. 2005, 2002b), and vardenafil (Prickaerts et al. 2002b; Rutten et al. 2007b) improved memory consolidation. In addition, Rutten et al. (2005) showed that sildenafil also improved memory consolidation in mice in this task. Previous work from our group showed that zaprinast reversed the object memory deficits induced by the NOS inhibitor 7-nitroindazole in rats in the object recognition task (Prickaerts et al. 1997). However, zaprinast was unable to reverse memory deficits in aged rats in this task (DomekLopacinska and Strosznajder 2008).

Several studies have shown spatial memory improvement in an adapted version of the elevated plus-maze in rats (Singh and Parle 2003) and mice (Patil et al. 2004a) after treatment with a PDE5-I. Furthermore, sildenafil treatment ameliorated the deficits induced by diabetes or ECS in this task (Patil et al. 2004a, 2006). Previous studies showed no effects of PDE5-Is on spatial tasks in healthy rats, i.e., the water escape task or the Y-maze (Prickaerts et al. 2004). However, since only one dose was tested in this study, further investigation will be needed. Finally, in hyperammonemia and portacaval shunt deficit models for liver failure, both sildenafil and zaprinast reversed spatial recognition deficits of rats in the Ymaze (Erceg et al. 2006, 2005a, b). Recent work adds to this since sildenafil reversed the effects the nitric oxide synthase (NOS) inhibitor L-NAME in a complex maze learning paradigm (Devan et al. 2006, 2007).

Furthermore, various studies investigated the effects of PDE5-Is on active and passive avoidance learning in rats, mice, and neonatal chicks. Although one study failed to show 
Table 5 Overview of effects of PDE5-Is on cognition

\begin{tabular}{|c|c|c|c|c|}
\hline $\begin{array}{l}\text { Task (cognitive process, } \\
\text { area involved) }\end{array}$ & Model (species) & Treatment & Results & Reference \\
\hline \multirow[t]{8}{*}{$\begin{array}{l}\text { Object recognition task } \\
\text { (object memory, } \\
\text { hippocampus and } \\
\text { rhinal cortex) }\end{array}$} & Unimpaired (rat) & $\begin{array}{l}\text { Sildenafil citrate }(1,3 \text {, or } \\
10 \mathrm{mg} / \mathrm{kg} \text {, p.o.) } 30 \mathrm{~min} \\
\text { before or immediately after } \\
\text { first trial ( } 24 \mathrm{~h} \text { interval } \\
\text { T1-T2) }\end{array}$ & $\begin{array}{l}\text { Sildenafil ( } 3 \mathrm{mg} / \mathrm{kg} \mathrm{T} 0 \text { or } \\
10 \mathrm{mg} / \mathrm{kg} \mathrm{T} 1-30 \mathrm{~min}) \\
\text { improves memory } \\
\text { consolidation }\end{array}$ & Prickaerts et al. (2005) \\
\hline & Unimpaired (rat) & $\begin{array}{l}\text { Zaprinast ( } 3 \text { or } 10 \mathrm{mg} / \mathrm{kg} \text {, } \\
\text { i.p.) immediately after first } \\
\text { trial ( } 4 \mathrm{~h} \text { interval } \mathrm{T} 1-\mathrm{T} 2)\end{array}$ & $\begin{array}{l}\text { Zaprinast }(10 \mathrm{mg} / \mathrm{kg}) \\
\text { improved memory } \\
\text { consolidation }\end{array}$ & Prickaerts et al. (1997) \\
\hline & Unimpaired (rat) & $\begin{array}{l}\text { Sildenafil }(1,3 \text {, or } 10 \mathrm{mg} / \mathrm{kg} \text {, } \\
\text { p.o.) immediately after first } \\
\text { trial }(24 \mathrm{~h} \text { interval } \mathrm{T} 1-\mathrm{T} 2)\end{array}$ & $\begin{array}{l}\text { Sildenafil }(3 \mathrm{mg} / \mathrm{kg}) \\
\text { improved memory } \\
\text { consolidation in ORT }\end{array}$ & Prickaerts et al. (2002b) \\
\hline & Unimpaired (rat) & $\begin{array}{l}\text { Vardenafil }(0.1,0.3,1 \text {, or } \\
3 \mathrm{mg} / \mathrm{kg} \text {, p.o.) immediately } \\
\text { after first trial }(24 \mathrm{~h} \\
\text { interval } \mathrm{T} 1-\mathrm{T} 2)\end{array}$ & $\begin{array}{l}\text { Vardenafil }(0.3 \mathrm{mg} / \mathrm{kg}) \\
\text { improved memory } \\
\text { consolidation in ORT }\end{array}$ & Prickaerts et al. (2002b) \\
\hline & Unimpaired (rat) & $\begin{array}{l}\text { Vardenafil ( } 1 \mathrm{mg} / \mathrm{kg}, \text { p.o. }) \\
\text { immediately after, } 1 \mathrm{~h}, 3 \mathrm{~h} \\
\text { or } 6 \mathrm{~h} \text { after first trial }(24 \mathrm{~h} \\
\text { interval } \mathrm{T} 1-\mathrm{T} 2)\end{array}$ & $\begin{array}{l}\text { Vardenafil (1 mg/kg } \\
\text { immediately after T1) } \\
\text { improved memory } \\
\text { consolidation in ORT }\end{array}$ & Rutten et al. (2007b) \\
\hline & Unimpaired (mouse) & $\begin{array}{l}\text { Sildenafil }(0.3,1 \text { or } 3 \mathrm{mg} / \mathrm{kg} \text {, } \\
\text { p.o.) immediately after first } \\
\text { trial }(24 \mathrm{~h} \text { interval } \mathrm{T} 1-\mathrm{T} 2)\end{array}$ & $\begin{array}{l}\text { Sildenafil }(1 \mathrm{mg} / \mathrm{kg}) \\
\text { improved memory } \\
\text { consolidation in ORT }\end{array}$ & Rutten et al. (2005) \\
\hline & $\begin{array}{l}\text { Impaired by NOS } \\
\text { inhibitor (rat) }\end{array}$ & $\begin{array}{l}\text { 7-nitroindazole (10 or } \\
30 \mathrm{mg} / \mathrm{kg} \text {, i.p.); zaprinast } \\
\text { ( } 3 \text { or } 10 \mathrm{mg} / \mathrm{kg} \text {, i.p.) } \\
\text { immediately after first trial } \\
\text { (1 h interval } \mathrm{T} 1-\mathrm{T} 2)\end{array}$ & $\begin{array}{l}\text { Zaprinast }(10 \mathrm{mg} / \mathrm{kg}) \\
\text { reversed the NOS-I } \\
(10 \mathrm{mg} / \mathrm{kg}) \text { deficit in ORT }\end{array}$ & Prickaerts et al. (1997) \\
\hline & $\begin{array}{l}\text { Impaired by age, } 3,12 \text {, } \\
\text { and } 24 \text { months old (rat) }\end{array}$ & $\begin{array}{l}\text { Zaprinast }(0.3 \mathrm{mg} / \mathrm{kg}, \text { s.c. }) \\
1 \mathrm{~h} \text { before first trial or } \\
\text { immediately after first trial } \\
(2 \mathrm{~h} \text { interval } \mathrm{T} 1-\mathrm{T} 2)\end{array}$ & $\begin{array}{l}\text { Zaprinast } 1 \mathrm{~h} \text { before } \mathrm{T} 1 \\
\text { improved acquisition in } \\
\text { 3-month-old animals. In } \\
\text { addition, it improved } \\
\text { consolidation in animals of } \\
3 \text { months when given } \\
\text { immediately after T1 }\end{array}$ & $\begin{array}{l}\text { Domek-Lopacinska and } \\
\text { Strosznajder (2008) }\end{array}$ \\
\hline \multirow[t]{4}{*}{$\begin{array}{l}\text { Adapted version of } \\
\text { elevated plus-maze } \\
\text { (spatial memory, } \\
\text { hippocampus) }\end{array}$} & Unimpaired (rat) & $\begin{array}{l}\text { Sildenafil }(2,4 \text {, or } 8 \mathrm{mg} / \mathrm{kg} \text {, } \\
\text { i.p.) } 30 \mathrm{~min} \text { before or } \\
\text { immediately after first trial }\end{array}$ & $\begin{array}{l}\text { Sildenafil }(8 \mathrm{mg} / \mathrm{kg}) \text { before } \\
\text { T1 marginally increased } \\
\text { spatial memory acquisition. } \\
\text { Sildenafil }(2,4,8 \mathrm{mg} / \mathrm{kg}) \\
\text { immediately after } \mathrm{T} 1 \\
\text { increased spatial memory } \\
\text { retention }\end{array}$ & Singh and Parle (2003) \\
\hline & $\begin{array}{l}\text { Unimpaired (mouse), } \\
\text { age-impaired (mouse) }\end{array}$ & $\begin{array}{l}\text { Sildenafil }(0.25,0.5 \text {, or } \\
1 \mathrm{mg} / \mathrm{kg} \text {, i.p. }) \text { immediately } \\
\text { after first trial }\end{array}$ & $\begin{array}{l}\text { Sildenafil improved spatial } \\
\text { memory performance in } \\
\text { young }(0.5 \text { and } 1.0 \mathrm{mg} / \mathrm{kg}) \\
\text { and aged }(0.25-1 \mathrm{mg} / \mathrm{kg}) \\
\text { animals }\end{array}$ & Patil et al. (2004a) \\
\hline & $\begin{array}{l}\text { Unimpaired (mouse), } \\
\text { age-impaired (mouse) }\end{array}$ & $\begin{array}{l}\text { Zaprinast }(0.5,1 \text { or } 2 \mathrm{mg} / \mathrm{kg} \text {, } \\
\text { i.p.) immediately after first } \\
\text { trial }\end{array}$ & $\begin{array}{l}\text { Zaprinast improved spatial } \\
\text { memory performance in } \\
\text { young }(1.0 \text { and } 2.0 \mathrm{mg} / \mathrm{kg}) \\
\text { and aged }(0.5-2 \mathrm{mg} / \mathrm{kg}) \\
\text { animals }\end{array}$ & Patil et al. (2004a) \\
\hline & $\begin{array}{l}\text { Impaired by diabetes- } \\
\text { STZ (rat) }\end{array}$ & $\begin{array}{l}\text { Streptozotocin (STZ) } \\
(60 \mathrm{mg} / \mathrm{kg} \text {, i.p.), sildenafil } \\
(0.25,0.5 \text {, or } 1 \mathrm{mg} / \mathrm{kg} \text {, i.p.) } \\
\text { immediately after training }\end{array}$ & $\begin{array}{l}\text { Sildenafil (all doses) } \\
\text { reversed STZ spatial } \\
\text { memory deficits }\end{array}$ & Patil et al. (2006) \\
\hline
\end{tabular}


Table 5 (continued)

\begin{tabular}{llll}
\hline $\begin{array}{l}\text { Task (cognitive process, } \\
\text { area involved) }\end{array}$ & Model (species) & Treatment & Results
\end{tabular}

\begin{tabular}{|c|c|c|c|c|}
\hline & $\begin{array}{l}\text { Impaired by diabetes- } \\
\text { LPS (mouse) }\end{array}$ & $\begin{array}{l}\text { Lipopolysaccharide (LPS: } \\
50 \mu \mathrm{g} \text {, i.p.) and sildenafil } \\
(0.25,0.5 \text {, or } 1 \mathrm{mg} / \mathrm{kg}, \text { i.p. }) \\
\text { or zaprinast }(0.5,1, \text { or } \\
2 \mathrm{mg} / \mathrm{kg} \text {, i.p.) immediately } \\
\text { after training }\end{array}$ & $\begin{array}{l}\text { Sildenafil }(0.5 \text { and } 1 \mathrm{mg} / \mathrm{kg}) \\
\text { and zaprinast ( } 1 \text { and } \\
2 \mathrm{mg} / \mathrm{kg}) \text { reversed LPS } \\
\text { spatial memory deficits }\end{array}$ & Patil et al. (2004a) \\
\hline & $\begin{array}{l}\text { Impaired by } \\
\text { electroconvulsive } \\
\text { shock (rat) }\end{array}$ & $\begin{array}{l}\text { Shocks }(0.2 \mathrm{~mA}, 0.2 \mathrm{~s} / \text { day } \\
\text { for } 15 \text { days }) \text { sildenafil } \\
(0.5,1 \text {, or } 2 \mathrm{mg} / \mathrm{kg} \text {, i.p. }) \\
\text { immediately after training }\end{array}$ & $\begin{array}{l}\text { Sildenafil (all doses) } \\
\text { reversed spatial memory } \\
\text { deficits }\end{array}$ & Patil et al. (2006) \\
\hline \multirow{4}{*}{$\begin{array}{l}\text { Y-maze (spatial memory, } \\
\text { hippocampus and } \\
\text { cerebellum) }\end{array}$} & Unimpaired (rat) & $\begin{array}{l}\text { Vardenafil ( } 3 \mathrm{mg} / \mathrm{kg} \text {, p.o.) } \\
\text { daily after last trial }\end{array}$ & $\begin{array}{l}\text { No effects on spatial } \\
\text { recognition }\end{array}$ & Prickaerts et al. (2004) \\
\hline & $\begin{array}{l}\text { Impaired by } \\
\text { hyperammonemia (rat) }\end{array}$ & $\begin{array}{l}\text { Sildenafil }(50 \mathrm{mg} / \mathrm{L}) \text { in } \\
\text { drinking water } 2 \text { days } \\
\text { before training }\end{array}$ & $\begin{array}{l}\text { Sildenafil (in drink water) } \\
\text { reversed spatial recognition } \\
\text { deficits }\end{array}$ & Erceg et al. (2006) \\
\hline & $\begin{array}{l}\text { Impaired by } \\
\text { hyperammonemia (rat) }\end{array}$ & $\begin{array}{l}\text { Ammonium acetate } \\
\text { containing diet ( } 28 \text { days } \\
\text { before testing), zaprinast } \\
\text { ( } 50 \mu \mathrm{M}, 0.25 \mu \mathrm{L} / \mathrm{h}, 2 \text { days } \\
\text { before testing) in cerebral } \\
\text { ventricle }\end{array}$ & $\begin{array}{l}\text { Zaprinast (through } \\
\text { minipump) reversed spatial } \\
\text { recognition deficits }\end{array}$ & Erceg et al. (2005a) \\
\hline & $\begin{array}{l}\text { Impaired by portacaval } \\
\text { shunts (rat) }\end{array}$ & $\begin{array}{l}\text { Portacaval shunt operation } \\
28 \text { days before test. } \\
\text { Sildenafil }(50 \mathrm{mg} / \mathrm{L}) \text { in } \\
\text { drinking water } 2 \text { days } \\
\text { before training }\end{array}$ & $\begin{array}{l}\text { Sildenafil (in drink water) } \\
\text { reversed spatial recognition } \\
\text { deficits }\end{array}$ & Erceg et al. (2005b) \\
\hline $\begin{array}{l}\text { Water escape task } \\
\text { (spatial memory, } \\
\text { (hippocampus) }\end{array}$ & Unimpaired (rat) & $\begin{array}{l}\text { Zaprinast }(10 \mathrm{mg} / \mathrm{kg} \text {, i.p.) } \\
\text { daily after last trial }\end{array}$ & $\begin{array}{l}\text { No effects on acquisition or } \\
\text { retention of spatial memory }\end{array}$ & Prickaerts et al. (2004) \\
\hline \multirow[t]{2}{*}{$\begin{array}{l}\text { Complex maze learning } \\
\text { (learning, } \\
\text { hippocampus) }\end{array}$} & $\begin{array}{l}\text { Impaired by NOS } \\
\text { inhibitor (rat) }\end{array}$ & $\begin{array}{l}\text { L-NAME ( } 60 \mathrm{mg} / \mathrm{kg} \text {, i.p.) } \\
30 \mathrm{~min} \text { before training, } \\
\text { sildenafil }(1,1.5,3 \text {, or } \\
4.5 \mathrm{mg} / \mathrm{kg} \text {, i.p. }) 15 \mathrm{~min} \\
\text { before training }\end{array}$ & $\begin{array}{l}\text { Sildenafil }(1.5 \mathrm{mg} / \mathrm{kg}) \\
\text { attenuated the L-NAME } \\
\text { deficit in maze learning }\end{array}$ & Devan et al. (2006) \\
\hline & $\begin{array}{l}\text { Impaired by NOS } \\
\text { inhibitor (rat) }\end{array}$ & $\begin{array}{l}\text { L-NAME }(0,45 \mu \mathrm{g} / \mathrm{kg} \text {, } \\
\text { i.c.v. } 30 \text { min before } \\
\text { training, sildenafil }(0,1.5 \text {, } \\
\text { or } 3 \mathrm{mg} / \mathrm{kg} \text {, i.p. }) 15 \mathrm{~min} \\
\text { before training }\end{array}$ & $\begin{array}{l}\text { Sildenafil }(3 \mathrm{mg} / \mathrm{kg}) \\
\text { attenuated the L-NAME } \\
\text { deficit in maze learning }\end{array}$ & Devan et al. (2007) \\
\hline \multirow[t]{2}{*}{$\begin{array}{l}\text { Active avoidance } \\
\text { learning (hippocampus) }\end{array}$} & $\begin{array}{l}\text { Impaired by scopolamine, } \\
0.75 \mathrm{mg} / \mathrm{kg} \text {, i.p., } 30 \mathrm{~min} \\
\text { before training } \\
\text { (rat) }\end{array}$ & $\begin{array}{l}\text { Sildenafil }(1.5,3 \text {, or } \\
4.5 \mathrm{mg} / \mathrm{kg} \text {, i.p. }) 15 \mathrm{~min} \\
\text { before training }\end{array}$ & $\begin{array}{l}\text { Sildenafil }(3 \mathrm{mg} / \mathrm{kg}) \text { reversed } \\
\text { the scopolamine deficit in } \\
\text { active avoidance task }\end{array}$ & Devan et al. (2004) \\
\hline & Unimpaired (mouse) & $\begin{array}{l}\text { Sildenafil }(1,3,10 \text {, or } \\
30 \mathrm{mg} / \mathrm{kg} \text {, i.p. }) 30 \mathrm{~min} \\
\text { before training or } \\
\text { immediately after training }\end{array}$ & $\begin{array}{l}\text { Sildenafil }(3 \mathrm{mg} / \mathrm{kg}) \\
\text { improved performance } \\
\text { (both } 30 \text { min before and } \\
\text { immediately after training) } \\
\text { in active avoidance }\end{array}$ & $\begin{array}{l}\text { Baratti and Boccia } \\
\text { (1999) }\end{array}$ \\
\hline \multirow[t]{2}{*}{$\begin{array}{l}\text { Passive avoidance } \\
\text { learning (hippocampus) }\end{array}$} & Unimpaired (rat) & $\begin{array}{l}\text { Sildenafil }(1,3,10 \text {, or } \\
20 \mathrm{mg} / \mathrm{kg} \text {, i.p. }) \text { immediately } \\
\text { after training in young and } \\
\text { old rats }\end{array}$ & $\begin{array}{l}\text { Sildenafil has no effect on } \\
\text { retention performance in } \\
\text { passive avoidance }\end{array}$ & Shafiei et al. (2006) \\
\hline & $\begin{array}{l}\text { Unimpaired (neonate } \\
\text { chick) }\end{array}$ & $\begin{array}{l}\text { Zaprinast }(0.1-750 \mu \mathrm{M} / \text { side, } \\
\text { i.c.) immediately after } \\
\text { training }\end{array}$ & $\begin{array}{l}\text { Zaprinast }(>100 \mu \mathrm{M}) \\
\text { enhanced early } \\
\text { consolidation }\end{array}$ & $\begin{array}{l}\text { Campbell and Edwards } \\
\text { (2006) }\end{array}$ \\
\hline
\end{tabular}


Table 5 (continued)

\begin{tabular}{|c|c|c|c|c|}
\hline $\begin{array}{l}\text { Task (cognitive process, } \\
\text { area involved) }\end{array}$ & Model (species) & Treatment & Results & Reference \\
\hline & $\begin{array}{l}\text { Unimpaired (young } \\
\text { chick) }\end{array}$ & $\begin{array}{l}\text { Zaprinast ( } 100 \mu \mathrm{M} / \text { side, i.c.) } \\
\text { immediately after training. } \\
\text { Retention times between } 10 \\
\text { and } 180 \mathrm{~min}\end{array}$ & $\begin{array}{l}\text { Zaprinast impaired } \\
\text { performance (at a retention } \\
\text { of } 40,60,90 \text {, and } 120 \mathrm{~min} \text { ) }\end{array}$ & $\begin{array}{l}\text { Edwards and Lindley } \\
(2007)\end{array}$ \\
\hline & $\begin{array}{l}\text { Unimpaired (mouse), } \\
\text { age-impaired (mouse) }\end{array}$ & $\begin{array}{l}\text { Sildenafil }(0.25,0.5 \text {, or } \\
1 \mathrm{mg} / \mathrm{kg} \text {, i.p. }) \text { immediately } \\
\text { after first trial }\end{array}$ & $\begin{array}{l}\text { Sildenafil improved } \\
\text { consolidation in young } \\
(0.5 \text { and } 1.0 \mathrm{mg} / \mathrm{kg}) \text { and } \\
\text { aged }(0.25-1 \mathrm{mg} / \mathrm{kg}) \\
\text { animals }\end{array}$ & Patil et al. (2004a) \\
\hline & $\begin{array}{l}\text { Unimpaired (mouse), } \\
\text { age-impaired (mouse) }\end{array}$ & $\begin{array}{l}\text { Zaprinast }(0.5,1 \text {, or } 2 \mathrm{mg} / \mathrm{kg} \text {, } \\
\text { i.p.) immediately after first } \\
\text { trial }\end{array}$ & $\begin{array}{l}\text { Zaprinast improved spatial } \\
\text { memory performance in } \\
\text { young }(1.0 \text { and } 2.0 \mathrm{mg} / \mathrm{kg}) \\
\text { and aged }(0.5-2 \mathrm{mg} / \mathrm{kg}) \\
\text { animals }\end{array}$ & Patil et al. (2004a) \\
\hline & $\begin{array}{l}\text { Impaired by diabetes } \\
\text { (rat) }\end{array}$ & $\begin{array}{l}\text { STZ }(60 \mathrm{mg} / \mathrm{kg} \text {, i.p. }) \text {, } \\
\text { sildenafil }(0.25,0.5 \text {, or } \\
1 \mathrm{mg} / \mathrm{kg} \text {, i.p.) immediately } \\
\text { after training }\end{array}$ & $\begin{array}{l}\text { Sildenafil (all doses) } \\
\text { reversed STZ memory } \\
\text { deficit caused by diabetes }\end{array}$ & Patil et al. (2006) \\
\hline & $\begin{array}{l}\text { Impaired by } \\
\text { electroconvulsive shock } \\
\text { (rat) }\end{array}$ & $\begin{array}{l}\text { Shocks }(0.2 \mathrm{~mA}, 0.2 \mathrm{~s} / \text { day } \\
\text { for } 15 \text { days }) \text {, sildenafil } \\
(0.5,1,2 \mathrm{mg} / \mathrm{kg} \text {, i.p. }) \\
\text { immediately after training }\end{array}$ & $\begin{array}{l}\text { Sildenafil (all doses) } \\
\text { reversed memory deficit } \\
\text { caused by ECS }\end{array}$ & Patil et al. (2006) \\
\hline & $\begin{array}{l}\text { Impaired by diabetes- } \\
\text { LPS (mouse) }\end{array}$ & $\begin{array}{l}\text { Lipopolysaccharide (LPS: } \\
50 \mu \mathrm{g}, \text { i.p. }) \text { and sildenafil } \\
(0.25,0.5 \text {, or } 1 \mathrm{mg} / \mathrm{kg}, \text { i.p.) } \\
\text { or zaprinast }(0.5,1, \\
2 \mathrm{mg} / \mathrm{kg} \text {, i.p.) immediately } \\
\text { after training }\end{array}$ & $\begin{array}{l}\text { Sildenafil }(0.5 \text { and } 1 \mathrm{mg} / \mathrm{kg}) \\
\text { and zaprinast }(1 \text { and } \\
2 \mathrm{mg} / \mathrm{kg} \text { ) reversed LPS } \\
\text { induced memory deficits }\end{array}$ & Patil et al. (2004b) \\
\hline $\begin{array}{l}\text { Object retrieval } \\
\text { (executive functioning } \\
\text { and response inhibition, } \\
\text { prefrontal cortex) }\end{array}$ & $\begin{array}{l}\text { Unimpaired } \\
\text { (cynomolgus macaque) }\end{array}$ & $\begin{array}{l}\text { Sildenafil }(0.3,1 \text {, or } \\
3 \mathrm{mg} / \mathrm{kg} \text {, i.m. }) 30 \mathrm{~min} \\
\text { before testing }\end{array}$ & $\begin{array}{l}\text { Sildenafil }(1,3 \mathrm{mg} / \mathrm{kg}) \\
\text { improved object retrieval } \\
\text { performance }\end{array}$ & Rutten et al. (2008a) \\
\hline $\begin{array}{l}\text { Seven different } \\
\text { psychophysical tests } \\
\text { (psychophysical } \\
\text { performance, various } \\
\text { brain areas) }\end{array}$ & Unimpaired (human) & $\begin{array}{l}\text { Sldenafil (100 mg, p.o.) } 1 \mathrm{~h} \\
\text { before testing }\end{array}$ & $\begin{array}{l}\text { Sildenafil enhanced } \\
\text { performance on the simple } \\
\text { reaction time test; other } \\
\text { tests no effect }\end{array}$ & Grass et al. (2001) \\
\hline $\begin{array}{l}\text { Auditory selective } \\
\text { attention and ERPs } \\
\text { (attention, prefrontal } \\
\text { cortex) }\end{array}$ & Unimpaired (human) & $\begin{array}{l}\text { Sldenafil (100 mg, p.o.) } 1 \mathrm{~h} \\
\text { before testing }\end{array}$ & $\begin{array}{l}\text { Sildenafil had no effect on } \\
\text { the behavioral } \\
\text { measurements of attention. } \\
\text { However, an increase in the } \\
\text { ERP components } \mathrm{Nd} \text { and } \\
\text { P3 indicates an } \\
\text { improvement of attention }\end{array}$ & Schultheiss et al. (2001) \\
\hline $\begin{array}{l}\text { Verbal recognition } \\
\text { memory and ERPs } \\
\text { (memory and } \\
\text { information processing, } \\
\text { hippocampus and } \\
\text { frontal cortex) }\end{array}$ & Unimpaired (human) & $\begin{array}{l}\text { Sildenafil (100 mg, p.o.) } 1 \mathrm{~h} \\
\text { before testing }\end{array}$ & $\begin{array}{l}\text { Sildenafil had no effect on } \\
\text { the behavioral } \\
\text { measurements of memory. } \\
\text { However, a reduction in } \\
\text { negativity between } 150 \text { and } \\
250 \mathrm{~ms} \text { might indicate an } \\
\text { effect on information } \\
\text { processing }\end{array}$ & Schultheiss et al. (2001) \\
\hline
\end{tabular}

i.c.v. intracerebroventricular, i.c. intracerebral, i.p. intraperitoneal, LPS lipopolysaccharide, NOS nitric oxide synthase, ORT object recognition task, p.o. per os, $T 1$ trial 1, T2 trial 2, STZ streptozotocin 
improvement in learning performance after sildenafil treatment in unimpaired and aged rats (Shafiei et al. 2006), others have shown improvements in unimpaired and aged mice and in neonatal chicks (Baratti and Boccia 1999; Campbell and Edwards 2006; Patil et al. 2004a). In contrast, Edwards and Lindley (2007) found that zaprinast could also have a negative effect on learning and memory when given at a high dose. Memory impairments in avoidance learning caused by scopolamine, diabetes, or ECS in rats were reversed by sildenafil treatment (Devan et al. 2004; Patil et al. 2006). In addition, zaprinast as well as sildenafil reversed memory deficits caused by a model for diabetes in mice (Patil et al. 2004a).

Finally, a recent study showed that the PDE5-I sildenafil dose-dependently improved performance in a prefrontal task, i.e., the object retrieval task (see above), in cynomolgus macaques (Rutten et al. 2008a).

Most research regarding the cognition-enhancing effects of PDE5-Is so far has focused on preclinical animal models; there are only two papers in which the effects of the PDE5-I sildenafil on human cognition were investigated. Grass et al. (2001) have shown that $100 \mathrm{mg}$ sildenafil enhanced performance in a simple reaction time test when given $1 \mathrm{~h}$ before testing. However, no effects were found on shortterm memory (STM), divided attention, and other psychomotor tasks (Grass et al. 2001). In addition, Schultheiss et al. (2001) studied the effects of sildenafil $(100 \mathrm{mg}, 1 \mathrm{~h}$ before testing) on auditory attention and word recognition. Again, no cognition-enhancing effects were found with regard to the behavioral measures

In both studies, STM tasks were performed that are thought to measure memory performance processes comparable to the object recognition task in rats. However, the object recognition task in animals usually measures more aspects of memory, such as that for object and for location, even though only the object memory itself might have been measured. The human tasks, on the other hand, only assess memory for words, pictures, or location, but never the combination of these aspects. Possibly, the fact that spatial information was lacking in the human studies has caused this discrepancy in findings.

Sildenafil changed certain components of event-related potentials (ERPs) in the study of Schultheiss et al. (2001). The Nd component, although it only showed a marginally significant effect, was increased after treatment with sildenafil. This indicates improved focused attention. The P3 component, which measures controlled processes of target selection, was significantly enhanced after the administration of sildenafil (Schultheiss et al. 2001). Again, this is evidence for improvements after treatment with sildenafil. Finally, a reduced negativity between 150 and $250 \mathrm{~ms}$ was found in the word recognition experiment after sildenafil treatment; this may also indicate an effect on information processing, although the exact role of this component remains uncertain (Schultheiss et al. 2001).

Several possible explanations for not finding any cognition-enhancing effects after PDE5-I treatment in humans in contrast to the results in animal studies exist. First, only one dose of sildenafil on one specific time point was tested in both studies. Investigating different doses, both higher and lower, at different administration time points might reveal possible cognition-enhancing effects in humans. In addition, a "ceiling effect" might have occurred in the cognitive tasks; this means that healthy subjects in these studies already perform at their maximal level, so their performance cannot be further improved. A final explanation might be that the number of participants was not sufficient, since only six participants were tested by Grass et al. (2001), whereas Schultheiss et al. (2001) examined ten healthy participants.

\section{PDE9}

To our knowledge, only one paper has been published in which the effects of PDE9 inhibition on cognition are described (Van der Staay et al. 2008). In this paper, the potent and selective PDE9-I BAY 73-6691 was used (Wunder et al. 2005). It was shown that this PDE9-I improved memory consolidation in unimpaired rats and mice in the object recognition and social recognition task (Van der Staay et al. 2008). Furthermore, this PDE9-I reversed the MK-801- or scopolamine-induced memory deficit in the Tmaze and the passive avoidance task, respectively (Van der Staay et al. 2008). More detailed information can be found in Table 6.

\section{PDE10}

Only very recently, PDE10-Is have become a target for CNS research, especially concerning the cognitive deficits related to schizophrenia (Schmidt et al. 2008). In the next section, a summary of the available literature on PDE10-Is and cognition will be given; a more detailed overview can be found in Table 7 .

Chronic treatment with the PDE10-I papaverine impaired spatial memory and reversal learning in unimpaired mice in the Morris water maze (Hebb et al. 2008). Administration of TP-10 did not have an effect on information processing in a prepulse inhibition task in unimpaired and MK-801impaired mice (Schmidt et al. 2008). However, TP-10 reversed the auditory gating deficit caused by D-amphetamine in rats (Schmidt et al. 2008). Papaverine improved attention in the attention shifting task in rats that were impaired by subchronic phenylcyclohexylpiperidine (PCP) treatment, a model of schizophrenia, whereas no effect was found in unimpaired rats (Rodefer et al. 2005). 
Table 6 Overview of effects of PDE9-I on cognition

\begin{tabular}{|c|c|c|c|c|}
\hline $\begin{array}{l}\text { Task (cognitive process, } \\
\text { area involved) }\end{array}$ & Model (species) & Treatment & Results & Reference \\
\hline $\begin{array}{l}\text { Object recognition task } \\
\text { (object memory, } \\
\text { hippocampus and rhinal } \\
\text { cortex) }\end{array}$ & Unimpaired (rat) & $\begin{array}{l}\text { BAY } 73-6691(0.1,0.3,1, \text { or } \\
3 \mathrm{mg} / \mathrm{kg}, \text { p.o. }) 30 \mathrm{~min} \text { before } \\
\text { T1 }(24 \mathrm{~h} \text { interval T1-T2) }\end{array}$ & $\begin{array}{l}\text { BAY 73-6691 }(0.1,0.3 \mathrm{mg} / \mathrm{kg}) \\
\text { had an intermediate effect on } \\
\text { memory consolidation }\end{array}$ & $\begin{array}{l}\text { Van der Staay et al. } \\
\text { (2008) }\end{array}$ \\
\hline $\begin{array}{l}\text { Passive avoidance } \\
\text { (learning, } \\
\text { hippocampus) }\end{array}$ & $\begin{array}{l}\text { Impaired by } \\
\text { scopolamine, } \\
0.03 \mathrm{mg} / \mathrm{kg} \text {, s.c., } \\
30 \mathrm{~min} \text { before } \\
\text { testing (rat) }\end{array}$ & $\begin{array}{l}\text { BAY } 73-6691(0.3,1 \text {, or } \\
3 \mathrm{mg} / \mathrm{kg} \text {, p.o.) } 60 \mathrm{~min} \text { before } \\
\text { testing }\end{array}$ & $\begin{array}{l}\text { BAY } 73-6691(1,3 \mathrm{mg} / \mathrm{kg}) \\
\text { attenuated the scopolamine- } \\
\text { induced retention deficit }\end{array}$ & $\begin{array}{l}\text { Van der Staay et al. } \\
(2008)\end{array}$ \\
\hline \multirow[t]{3}{*}{$\begin{array}{l}\text { Social recognition (social } \\
\text { memory, hippocampus } \\
\text { and amygdala) }\end{array}$} & Unimpaired (rat) & $\begin{array}{l}\text { BAY } 73-6691(0,0.03,0.3, \\
\text { or } 3 \mathrm{mg} / \mathrm{kg}, \mathrm{p} . \mathrm{o} .) 60 \mathrm{~min} \text { before } \\
\text { the first trial }(\mathrm{T} 1) \text {, immediately } \\
\text { after } \mathrm{T} 1 \text { or } 60 \mathrm{~min} \text { before trial } 2(\mathrm{~T} 2) \\
(24 \mathrm{~h} \text { interval } \mathrm{T} 1-\mathrm{T} 2)\end{array}$ & $\begin{array}{l}\text { BAY 73-6691 }(0.3,3 \mathrm{mg} / \mathrm{kg}) \\
60 \mathrm{~min} \text { before } \mathrm{T} 1, \text { or BAY } \\
73-6691(0.03,0.3,3 \mathrm{mg} / \mathrm{kg}) \\
\text { immediately after } \mathrm{T} 1 \text { and } \\
60 \text { min before T2 improved } \\
\text { memory consolidation }\end{array}$ & $\begin{array}{l}\text { Van der Staay et al. } \\
\text { (2008) }\end{array}$ \\
\hline & Unimpaired (rat) & $\begin{array}{l}\text { BAY } 73-6691(0 \text { or } 1 \mathrm{mg} / \mathrm{kg} \text {, p.o. }) \\
60 \mathrm{~min} \text { before the first trial (T1) } \\
\text { with a familiar juvenile or BAY } \\
73-6691(1 \mathrm{mg} / \mathrm{kg} \text {, p.o.) } 60 \mathrm{~min} \\
\text { before the first trial (T1) with a } \\
\text { novel juvenile ( } 24 \mathrm{~h} \text { interval } \\
\text { T1-T2) }\end{array}$ & $\begin{array}{l}\text { BAY 73-6691 (1 mg/kg) } \\
\text { improved memory } \\
\text { consolidation with a } \\
\text { familiar as well as a novel } \\
\text { juvenile }\end{array}$ & $\begin{array}{l}\text { Van der Staay et al. } \\
(2008)\end{array}$ \\
\hline & Unimpaired (mouse) & $\begin{array}{l}\text { BAY } 73-6691(0,0.03,0.3 \text {, or } \\
3 \mathrm{mg} / \mathrm{kg} \text {, p.o.) } 30 \mathrm{~min} \text { before the } \\
\text { first trial ( } 24 \mathrm{~h} \text { interval } \mathrm{T} 1-\mathrm{T} 2)\end{array}$ & $\begin{array}{l}\text { BAY } 73-6691(0.3,3 \mathrm{mg} / \mathrm{kg}) \\
30 \text { min before } \mathrm{T} 1 \text { improved } \\
\text { memory consolidation }\end{array}$ & $\begin{array}{l}\text { Van der Staay et al. } \\
(2008)\end{array}$ \\
\hline $\begin{array}{l}\text { T-maze (working } \\
\text { memory, } \\
\text { hippocampus) }\end{array}$ & $\begin{array}{l}\text { Impaired by } \mathrm{MK}-801 \text {, } \\
0.06 \mathrm{mg} / \mathrm{kg} \text {, s.c., } \\
30 \mathrm{~min} \text { before testing } \\
\text { (mouse) }\end{array}$ & $\begin{array}{l}\text { BAY } 73-6691(0,1,3 \text {, or } \\
10 \mathrm{mg} / \mathrm{kg}, \text { p.o. }) 60 \mathrm{~min} \text { before } \\
\text { testing }\end{array}$ & $\begin{array}{l}\text { BAY } 73-6691(10 \mathrm{mg} / \mathrm{kg}) \\
\text { attenuated the MK-801 } \\
\text { induced deficit in alternation } \\
\text { rate }\end{array}$ & $\begin{array}{l}\text { Van der Staay et al. } \\
(2008)\end{array}$ \\
\hline
\end{tabular}

p.o. per os, $T 1$ trial 1, T2 trial 2, s.c. subcutaneous

Several studies also used KO models to study the role of PDE10 in cognition. It was shown that PDE10A knockout in a DBA1LacJ background had no effect on learning and memory in the passive avoidance and water escape task in mice (Siuciak et al. 2006, 2008b). In addition, these mice showed the same conditioned avoidance response as wild-type mice; however, these $\mathrm{KO}$ mice required more training to reach the performance of wild-type animals (Siuciak et al. 2006, 2008b). On the other hand, PDE10A KO mice with a $\mathrm{C} 57 \mathrm{BL} / 6 \mathrm{~N}$ background were unable to reach the performance of the wild-type mice in this task (Siuciak et al. 2008b).

The data discussed in the previous paragraphs showed that PDE10-Is can improve cognition in impaired animals, but can also induce a cognitive impairment in healthy animals. There are several explanations that might account for these contradictory findings. First, the cognitive impairment in healthy animals caused by papaverine was the result of a subchronic treatment, which was not found after acute treatment in impaired animals. Secondly, different aspects of cognition were addressed in these studies. In the healthy animals, learning and memory were studied, whereas in the impaired animals, information processing and attention were investigated. Thirdly, improving cognition of a healthy individual is not the same as restoring impaired cognition; the underlying processes, and thus the effect of a compound, may differ.

\section{Mechanisms of action}

There are several mechanisms of action which could account for the cognition-enhancing effects of PDE-Is. First, it has been proposed that these effects could be the result of vasodilatory properties of PDE-Is. Secondly, cognition enhancement could be a consequence of emotional arousal. Finally, positive effects may be due to enhanced second messenger signaling (cAMP and/or cGMP) resulting in facilitated LTP processes. All three mechanisms will be discussed in the next sections. 
Table 7 Overview of effects of PDE10-Is on cognition

\begin{tabular}{|c|c|c|c|c|}
\hline $\begin{array}{l}\text { Task (cognitive } \\
\text { process, area } \\
\text { involved) }\end{array}$ & Model (species) & Treatment & Results & Reference \\
\hline \multirow[t]{2}{*}{$\begin{array}{l}\text { Passive avoidance } \\
\text { learning } \\
\text { (hippocampus) }\end{array}$} & $\begin{array}{l}\text { Impaired PDE10A } \\
\text { KO (mouse) }\end{array}$ & - & $\begin{array}{l}\text { Apparent effect, but this } \\
\text { could be explained by a } \\
\text { locomotor effect }\end{array}$ & Siuciak et al. (2006) \\
\hline & $\begin{array}{l}\text { Impaired PDE10A } \\
\text { KO (mouse) }\end{array}$ & - & No effect & Siuciak et al. (2008b) \\
\hline \multirow{3}{*}{$\begin{array}{l}\text { Acquisition of } \\
\text { conditioned avoidance } \\
\text { responding (CAR) } \\
\text { (learning, } \\
\text { hippocampus) }\end{array}$} & $\begin{array}{l}\text { Impaired PDE10A } \\
\text { KO (mouse) }\end{array}$ & - & $\begin{array}{l}\text { PDE10A-/- mice learned } \\
\text { the task as well as PDE10A } \\
+/+ \text { mice, but needed more } \\
\text { training }\end{array}$ & Siuciak et al. (2006) \\
\hline & $\begin{array}{l}\text { Impaired by PDE10A } \\
\text { KO; DBA1LacJ } \\
\text { background (mouse) }\end{array}$ & - & $\begin{array}{l}\text { KO mice learned the task as } \\
\text { well as WT, but needed } \\
\text { more training }\end{array}$ & Siuciak et al. (2008b) \\
\hline & $\begin{array}{l}\text { Impaired by PDE10A } \\
\text { KO; C57BL/6N } \\
\text { background (mouse) }\end{array}$ & - & $\begin{array}{l}\text { KO mice learned needed } \\
\text { more training and did not } \\
\text { reach performance of } \mathrm{WT}\end{array}$ & Siuciak et al. (2008b) \\
\hline \multirow[t]{2}{*}{$\begin{array}{l}\text { Morris water maze } \\
\text { (spatial memory, } \\
\text { hippocampus) }\end{array}$} & $\begin{array}{l}\text { Impaired PDE10A KO } \\
\text { (mouse) }\end{array}$ & - & $\begin{array}{l}\text { Apparent effect, but this } \\
\text { could be explained by a } \\
\text { locomotor effect }\end{array}$ & Siuciak et al. (2006) \\
\hline & Unimpaired (mouse) & $\begin{array}{l}\text { Chronic treatment of papaverine } \\
(0,5,10, \text { or } 20 \mathrm{mg} / \mathrm{kg}, \text { s.c. }) \\
\text { daily for } 14 \text { days. Then, } \\
\text { same treatment either prior } \\
\text { of } 30 \text { min after testing }\end{array}$ & $\begin{array}{l}\text { Papaverine }(5 \mathrm{mg} / \mathrm{kg} \text {, after } \\
\text { testing) impaired latency } \\
\text { and distance. In addition, } \\
\text { papaverine }(20 \mathrm{mg} / \mathrm{kg} \text {, } \\
30 \mathrm{~min} \text { before testing and } \\
5 \mathrm{mg} / \mathrm{kg}, 30 \mathrm{~min} \text { after } \\
\text { testing) increased the time } \\
\text { spend in the old platform } \\
\text { quadrant in reversal learning }\end{array}$ & Hebb et al. (2008) \\
\hline $\begin{array}{l}\text { Auditory gating } \\
\text { (anesthetized) } \\
\text { (information } \\
\text { processing, frontal } \\
\text { cortex) }\end{array}$ & $\begin{array}{l}\text { Impaired by D-amphetamine, } \\
1 \mathrm{mg} / \mathrm{kg} \text {, i.v., } 5 \text { min before } \\
\text { testing (rat) }\end{array}$ & $\begin{array}{l}\mathrm{TP}-10(0,3 \mathrm{mg} / \mathrm{kg}) ; 5 \mathrm{~min} \\
\text { before testing }\end{array}$ & $\begin{array}{l}\text { TP-10 reversed auditory } \\
\text { gating deficit }\end{array}$ & Schmidt et al. (2008) \\
\hline \multirow{2}{*}{$\begin{array}{l}\text { Prepulse inhibition } \\
\text { (information } \\
\text { processing, } \\
\text { frontal cortex) }\end{array}$} & Unimpaired (mouse) & $\begin{array}{l}\mathrm{TP}-10(0,0.32,1,3.2 \text {, or } \\
10 \mathrm{mg} / \mathrm{kg} \text {, s.c. }) 30 \mathrm{~min} \\
\text { before testing }\end{array}$ & $\begin{array}{l}\text { TP-10 had no effect on PPI } \\
\text { or startle response }\end{array}$ & Schmidt et al. (2008) \\
\hline & $\begin{array}{l}\text { Impaired by MK- } 801 \text {, } \\
0.178 \mathrm{mg} / \mathrm{kg}, \text { s.c., } 30 \mathrm{~min} \\
\text { before testing (mouse) }\end{array}$ & $\begin{array}{l}\mathrm{TP}-10(0,1,3.2, \text { or } \\
10 \mathrm{mg} / \mathrm{kg}, \text { s.c. }) 30 \mathrm{~min} \\
\text { before testing }\end{array}$ & $\begin{array}{l}\text { TP-10 did not reverse PPI } \\
\text { deficit }\end{array}$ & Schmidt et al. (2008) \\
\hline $\begin{array}{l}\text { Attention set-shifting } \\
\text { task (attention, } \\
\text { prefrontal cortex) }\end{array}$ & $\begin{array}{l}\text { Impaired by subchronic PCP } \\
\text { treatment, } 5 \mathrm{mg} / \mathrm{kg} \text {, i.p., } \\
\text { twice a day for } 7 \text { days (rat) }\end{array}$ & $\begin{array}{l}\text { Papaverine }(0,3,10 \text {, or } \\
30 \mathrm{mg} / \mathrm{kg} \text {, i.p. })\end{array}$ & $\begin{array}{l}\text { Papaverine attenuated PCP } \\
\text { induced deficits at all doses. } \\
\text { No effect of papaverine on } \\
\text { saline treated rats }\end{array}$ & Rodefer et al. (2005) \\
\hline
\end{tabular}

$C A R$ conditioned avoidance responding, i.p. intraperitoneal, i.v. intravenous, $K O$ knockout, $P C P$ phenylcyclohexylpiperidine, $P P I$ prepulse inhibition, s.c. subcutaneous

\section{Blood flow}

An increase in blood flow and concomitantly an increase in glucose metabolism might be related to the observed cognitive enhancements after PDE-I treatments as predominantly investigated and observed in rodents. This is because PDE-Is increase the levels of cAMP and cGMP, and vasodilatation properties can be attributed to both cyclic nucleotides (Dundore et al. 1993; Paterno et al. 1996).

Summarizing the rodent behavioral data with PDE5 inhibition (see Table 5), it appears that zaprinast and sildenafil are optimally effective at an oral dose of approximately 10 and $3 \mathrm{mg} / \mathrm{kg}$, respectively. The effects of both zaprinast and sildenafil on blood pressure, which is negatively related to 
blood flow, have been sparsely investigated in conscious rodents. Administration of zaprinast does not decrease the mean arterial blood pressure at a dose of $2 \mathrm{mg} / \mathrm{kg}$ (i.p.) in mice (Patil et al. 2004a) and $10 \mathrm{mg} / \mathrm{kg}$ (p.o.) in rats (Prickaerts et al. 1997). Yet, a decrease in blood pressure can be observed with zaprinast after systemic administration (i.v.) of doses higher than $10 \mathrm{mg} / \mathrm{kg}$ (Dundore et al. 1993).

One milligram per kilogram sildenafil (i.p.) did not affect the mean arterial blood pressure in mice up to $6 \mathrm{~h}$ after administration (Patil et al. 2004a). Yet sildenafil can decrease the mean arterial blood pressure up to $6 \mathrm{~h}$, but an oral dose of at least $10 \mathrm{mg} / \mathrm{kg}$ was needed in rats (Rehse et al. 1999). Sildenafil has also been tested directly on cerebral blood flow as measured with laser Doppler flowmetry, although rats need to be anesthetized for this technique (Zhang et al. 2002). Surprisingly, localized cerebral blood flow was increased after oral administration of $2 \mathrm{mg} / \mathrm{kg}$ sildenafil.

Cerebral blood flow and glucose utilization have been investigated in mice with the $\left[{ }^{13} \mathrm{~N}\right]$ ammonia uptake and $\left[{ }^{3} \mathrm{H}\right]$ 2-deoxyglucose uptake technique (Ishikawa et al. 2002). It was found that, within $5 \mathrm{~min}$ after $3 \mathrm{mg} / \mathrm{kg}$ rolipram (i.p.) administration, blood flow and glucose metabolism in the brain were both decreased by approximately $20 \%$ and $40 \%$, respectively. At $30 \mathrm{~min}$ after administration, glucose use was still decreased by $60 \%$. One milligram per kilogram rolipram was also tested on central glucose use, which was found to be decreased by $40 \%$ at $15 \mathrm{~min}$ after administration. Of note, these doses of rolipram are rather high and behaviorally effective doses are in general below $1 \mathrm{mg} / \mathrm{kg}$ (i.p.) (see Table 4). Increasing the dose of rolipram above $1 \mathrm{mg} / \mathrm{kg}$ will only result in sedation and locomotor depression.

Taken together, the PDE4-Is and PDE5-Is tested in rodents can have peripheral and central vascular and metabolic effects, but these effects occur after treatment with doses that are higher than required for cognition enhancement. Moreover, detailed inspection of the behavioral data already suggests that a uniform cerebrovascular effect is not sufficient to explain the differential effects on cognitive processes. For instance, administration of a cGMP analog into the hippocampus improved early consolidation, whereas a comparable cAMP analog had no effect (Bernabeu et al. 1996; Prickaerts et al. 2002a). Along similar lines, sildenafil improved early consolidation, whereas rolipram did not (Rutten et al. 2007b). On the other hand, late consolidation processes are improved by rolipram while sildenafil is ineffective. Once more, these findings indicate that it is not likely that cerebrovascular and metabolic effects explain the cognitive improvements as observed in rodents.

Sildenafil $100 \mathrm{mg}$ has effects on the CNS of humans as evident from influenced evoked potential and reaction times (Grass et al. 2001; Schultheiss et al. 2001). The same dose of sildenafil has been shown to increase heart rate and decreased diastolic blood pressure in healthy subjects (Kruuse et al. 2002). However, sildenafil had no effect on blood flow in the middle cerebral artery, just as there were no changes in radial and temporal artery diameters (Arnavaz et al. 2003; Kruuse et al. 2002). This indicates that the effects on cognition after sildenafil administration are not likely to be related to cerebrovascular mechanisms in humans as well.

\section{Emotional arousal}

Anecdotic report and case studies describe emotional arousal (anxiety, aggression) in men taking sildenafil (Milman and Arnold 2002). In rats, it has been demonstrated that sildenafil $(1-3 \mathrm{mg} / \mathrm{kg}$ ) has an anxiogenic effect (Kurt et al. 2004). Effects on emotion and arousal are likely since animal studies have shown that central cGMP is involved in sympathetic activation (Krukoff 1998). Concomitantly, anxiolytics including benzodiazepines reduced the stress-induced increase in central cGMP levels (Tang et al. 1997). cAMP levels were reduced as well after benzodiazepines administration, as found in vitro (Niles and Wang 1999); although increases in cAMP have also been observed (Cherry et al. 2001). In line with the latter observation, PDE4-I rolipram $(0.1 \mathrm{mg} / \mathrm{kg}$, s.c. $)$ had an anxiolytic effect in rats (Silvestre et al. 1999). Yet it has to be noted again that the dose of rolipram is still relatively high and decreased locomotor activity might have interfered with the behavioral response. Nevertheless, it is evident that the cyclic nucleotides cAMP and cGMP play a role in arousal and emotional processes. Emotional arousal, to a certain maximum, is necessary for an optimal cognitive performance (Prickaerts and Steckler 2005). Thus, the effects of PDE-Is on cognition can be influenced by or attributed to effects on processes of emotions and arousal.

\section{Long-term potentiation}

Hippocampal LTP is the most established cellular model for the neuroplastic mechanisms that underlie learning and memory (Bliss and Collingridge 1993). LTP is described by the increase in the chemical strength of a synapse after tetanus stimulation that lasts for over an hour. Experimentally, series of short, high-frequency electric stimulations to a nerve cell synapse can strengthen or potentiate that synapse for several minutes to hours. Glutamate induces LTP via the activation of the ionotropic NMDA receptor, after which calcium enters the cell triggering various presynaptic and postsynaptic changes. The mechanism of LTP and its relationship to learning and memory is quite complicated. It depends on the fine-tuning of various components of the glutamatergic system including ionotropic and metabotropic glutamate receptors, other neurochemical systems, second messengers, and signal transduction pathways. Hippocampal LTP can, depending on the induction paradigm, last for less than $3 \mathrm{~h}$ or longer. The former is called early-phase LTP (E- 
LTP) and the latter late-phase LTP (L-LTP). It has been suggested that E-LTP (or LTP1) can be transformed into LLTP (LTP3), probably via an intermediate LTP2 form (Reymann and Frey 2007). Furthermore, it has been assumed that E-LTP is related to STM and L-LTP to LTM (Izquierdo et al. 2002).

In general, both presynaptic and postsynaptic mechanisms are related to LTP and can involve the second messengers cAMP and cGMP. Figure 1 provides a schematic overview of the cellular processes related to LTP and second messenger signaling. More in detail, a postsynaptic cAMP/PKA/CREB pathway (Impey et al. 1996) and cGMP/PKG/CREB pathway ( $\mathrm{Lu}$ et al. 1999) are involved in L-LTP. A postsynaptic calmodulin-dependent protein kinase II (CaMKII) pathway (Sweatt 1999) and presynaptic cGMP/PKG pathway (Arancio et al. 1995) have been implicated in E-LTP.

Since PDE-Is influence the levels of the second messengers cAMP and/or cGMP, it can be argued that the procognitive effects of PDE-Is are related to the facilitation of LTP. Yet, only a limited number of studies has investigated the effects of PDE-Is on LTP. Most research has been aimed at the effects of PDE4 inhibition on LTP. The PDE4-I rolipram, when applied to hippocampal slices, has been shown to facilitate hippocampal LTP in rats and mice (Ahmed and Frey 2003, 2005; Gong et al. 2004; Navakkode et al. 2004, 2005). In addition, we recently demonstrated that the PDE9-I BAY 73-6691

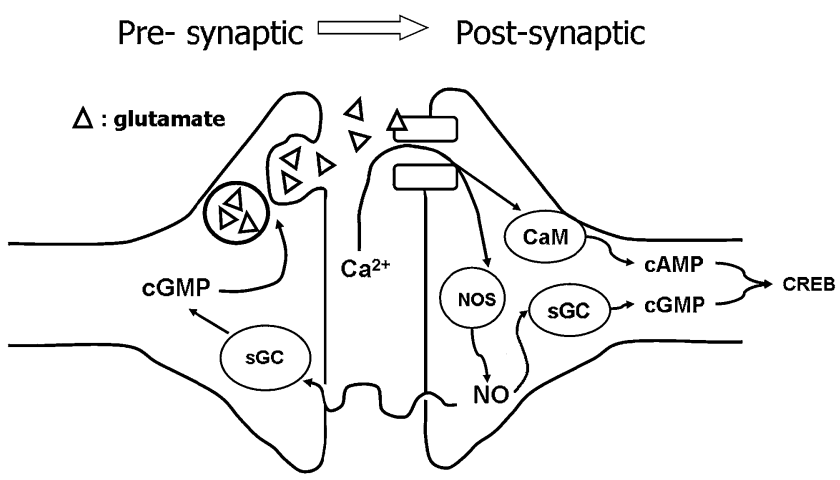

Fig. $1 \mathrm{Ca}^{2+}$ entry through the postsynaptic ionotropic NMDA receptor triggers LTP induction. $\mathrm{Ca}^{2+}$ results in the activation of CaMKII (a specific form of CaMK). Activated CaMKII stimulates the insertion into the membrane of the ionotropic AMPA receptor, which is involved in regular signal transduction through the generation of excitatory postsynaptic potentials. In addition, CaMKII activates AC resulting in the production of the second messenger cAMP. The latter activates PKA, which has a positive effect on the transcription factor CREB (via MAP kinases possibly). CREB activation is known to result in an increased gene expression, including the genes for AMPA receptors and thus future signal transduction is enhanced. $\mathrm{Ca}^{2+}$ is also known to activate the enzyme NOS, which produces NO. The latter can activate GC, which produces the second messenger cGMP. There are indications that, postsynaptically, cGMP has similar effects as cAMP, but via the activation of PKG. NO is also known to act as a retrograde messenger and can thus stimulate presynaptic GC. It has been found that cGMP stimulates the synthesis and release of glutamate via PKG amplified E-LTP elicited by weak tetanic stimulation in young Wistar rats (Van der Staay et al. 2008). These findings are in line with observations of enhanced E-LTP after treatment with the PDE2-I BAY 60-7550 in rats (Boess et al. 2004). Finally, chronic administration ( $1 \mathrm{mg} / \mathrm{kg} /$ day, i.p.), for 15 days, of the PDE5-I sildenafil improved LTP in CA3CA1 synapses of hippocampal slices in mice (Uthayathas et al. 2007). To our knowledge, no studies have investigated the effects of PDE10 inhibition on LTP. The few existing studies that investigated the effects of PDE-Is on LTP indicate that inhibition of PDEs may have a beneficial effect on synaptic plasticity. Since LTP is considered the underlying mechanism for learning and memory, it is relevant to evaluate the effects of PDE-Is on LTP in addition to and in parallel with behavioral studies.

The process opposed to LTP is long-term depression (LTD), which decreases or depresses the strength of a synapse for a certain amount of time as a result of either strong or persistent weak stimulation. Several studies have shown that PDE4-Is and PDE5-Is can induce or reinforce LTD in the hippocampus and the striatum among others (Bailey et al. 2003; Calabresi et al. 1999; Navakkode et al. 2005). Recently, it has been found that a deficit in LTD can result in memory impairment (Griffiths et al. 2008), which is in line with the theoretical neural network models that depend on bidirectional synaptic plasticity (LTP and LTD) to mediate learning and memory (Malenka 1994). Accordingly, it is now evident that, besides excitatory strengthening mechanisms in LTP, stabilization or suppression mechanisms, e.g., LTD, are also crucial for the regulation of synaptic plasticity (Abel et al. 1998). However, the exact underlying mechanisms remain elusive and the role of PDE-Is in these processes require further investigation.

\section{Time windows in memory processes}

PDE2, PDE4, and PDE9 inhibition improved both STM and LTM (see Tables 3, 4, and 6). PDE5 inhibition has only been investigated for LTM. Yet, based on the PDE9-I experiments (Van der Staay et al. 2008), it might be expected that PDE5 inhibition will result in STM improvements, though this needs to be confirmed in future studies. Taken together, treatment of rodents with different types of selective PDE-Is, which inhibit the degradation of the second messengers cAMP and/or cGMP, improved their STM as well as LTM. Furthermore, with respect to LTM, it appears that, for consolidation processes, a distinction can be made between early consolidation $(<3 \mathrm{~h})$ and late consolidation $(>3 \mathrm{~h})$ with cGMP being involved in the former and cAMP in the latter (Bernabeu et al. 1996; Izquierdo et al. 2006; Prickaerts et al. 2002a; Rutten et al. 2007b). These findings suggest that different underlying mechanisms should explain consolida- 
tion processes. Or, in more detail, are different forms of LTP involved in different phases of LTM consolidation?

Defining STM as not requiring protein synthesis may implicate that the time window of E-LTP corresponds with the duration of STM (1-3 h) (Izquierdo et al. 2002). Presynaptic cGMP is involved in E-LTP (LTP1) (Arancio et al. 1995), but cAMP is probably not (Nguyen and Woo 2003). Thus, it can be argued that rolipram should not improve STM. However, we found that rolipram can improve STM (Rutten et al. 2006). This effect might be explained by a general enhancement of synaptic transmission by increasing neurotransmitter availability, as rolipram has been found to activate the cognition-related cholinergic system (Imanishi et al. 1997), and also the noradrenergic and dopaminergic neurotransmitter systems (Schoffelmeer et al. 1985).

L-LTP (LTP2 and LTP3) is dependent on protein synthesis and last longer than $3 \mathrm{~h}$ (Reymann and Frey 2007). It can be assumed that L-LTP is related to LTM. Figure 2 illustrates the interrelationship between STM and LTM with intermediate memory (IM) in between STM and LTM. It might be speculated that LTP2 is representing early consolidation/IM and LTP3 represents late consolidation/LTM. These questions clearly warrant further investigations.

E-LTP can be converted into L-LTP (Pang et al. 2004). This is in line with the idea that information in the STM can be transferred into LTM (Baddeley 2003). As presynaptic
cGMP plays a role in E-LTP, theoretically, inhibition of cGMP degradation with, for instance, a PDE9-I should, therefore, be able to influence L-LTP/LTM via E-LTP/STM as well. But cGMP as well as cAMP are involved in postsynaptic L-LTP processes resulting in phosphorylation of the transcription factor CREB eventually. However, as described above, both cyclic nucleotides have different effects on consolidation processes. This implies that the signal transduction pathways are far more complex than known thus far. It seems likely that additional modulators are involved in regulating and mediating the timed effect of the second messengers cGMP and cAMP on memory processes.

\section{Targeting cognitive functioning}

The application of PDE-Is in studies of animal cognition enhancement has been fruitful. These studies have extended our fundamental knowledge about the possible underlying cellular and molecular mechanisms of learning, memory, and other cognitive functions. However, to predict which classes of PDE-Is are possibly the most effective cognition enhancers, in either preclinical or clinical studies, depends on various factors.

First, it is important to know the exact localization of specific PDE enzymes in the normal brain (see also Table 1).

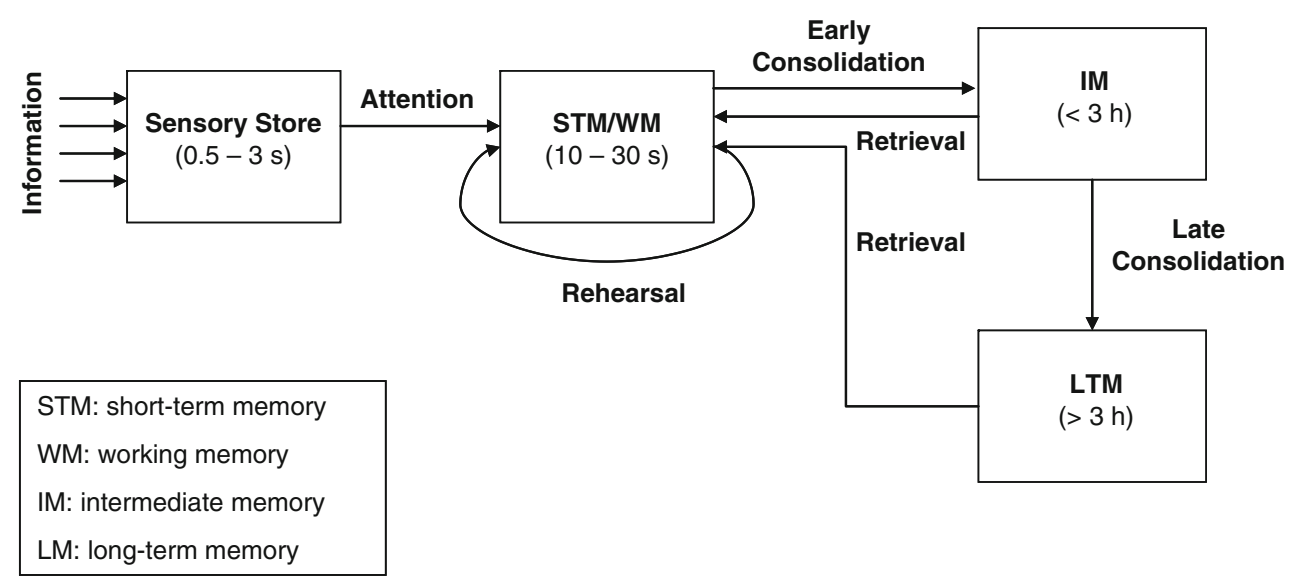

Fig. 2 A schematic classification of memory identifying four distinct types of memory stages: sensory store, short-term memory (STM)/ working memory $(W M)$, intermediate memory $(I M)$, and long-term memory $(L T M)$. In the sensory store, all the incoming information from the sensory organs is accumulated and, depending on attention processes certain items, can be transferred to STM/WM (Baddeley 2003). These stores generally have limited capacity and duration. Information can be stored for a longer period of time ranging from hours to years. It is suggested that there are two stages involved, that is, IM and LTM (Kesner and Hopkins 2006). The time frames of the three stages of STM, IM, and LTM are not clearly defined and depend on the definitions used by the researcher. In addition, the exact role of different brain areas in this respect is not fully clear yet. But it is evident that the hippocampus plays a key role and is particularly involved in IM processes (Kesner and Hopkins 2006). We propose that information is processed from STM to IM via early consolidation and subsequently from IM to LTM via late consolidation. In addition, we assume that STM is supported by transient changes in neuronal transmission, not requiring gene expression and protein synthesis whereas IM and LTM are maintained by more stable and permanent neuronal changes that are dependent on protein synthesis (Izquierdo et al. 2002). cGMP-specific PDE-Is might be able to influence STM via enhanced LTP1. In addition, cAMP-specific PDE-Is influence STM probably via an increased neurotransmitter release directly. Furthermore, LTP2 might represent IM and should be specifically influenced by cGMP-specific PDE inhibition. Finally, LTM is likely represented by LTP3 which should be influenced by cAMP-specific PDE inhibition 
The localization of the enzymes might predict that certain cognitive functions that are primarily located in specific brain structures may be enhanced by some PDE-Is, but not by others. For example, PDE10 is predominantly expressed in striatal areas (Schmidt et al. 2008) and is, therefore, a target for schizophrenia. In contrast, PDE4 is highly expressed in the hippocampus and cortex (Perez-Torres et al. 2000) and is, therefore, considered a better target for cognition enhancement. Of note, the development of a specific antibody against a selective PDE, preferentially of the level of isoform type, will more specifically target a PDE for a certain cognitive function (Fujita et al. 2007).

Secondly, it must be taken into account that the constitution of the brain changes with age and the distribution of PDEs can be modified by the aging process As a consequence, a PDE-I can improve cognition in young subjects, but impair cognition in old subjects. Likewise, Ramos et al. (2003) demonstrated that rolipram had a positive effect on prefrontal cortexdependent working memory in young rhesus monkeys, but had a negative effect on working memory in aged rhesus monkeys. However, rolipram improved performance in the passive avoidance task, a test of hippocampus-dependent memory, in both young and aged mice (Barad et al. 1998). With advancing age, opposite profiles between the function of PKA in the hippocampus and prefrontal cortex were suggested to explain the results of Ramos et al. (2003), i.e., the prefrontal cortex showed indices of increased PKA activity, while the hippocampus exhibited evidence of decreased PKA activity (Ramos et al. 2003). In addition, is has been shown that expression of PDE5 is strongly reduced in brains of Alzheimer's disease patients (Reyes-Irisarri et al. 2007). However, PDE2 and PDE9 do not show this Alzheimerrelated reduction in expression patterns, but show the same distribution as in healthy age-matched controls (Reyes-Irisarri et al. 2007). Along similar lines, PDE5 inhibition did not improve object memory in aged rats (Domek-Lopacinska and Strosznajder 2008). Consequently, when developing a PDE-I for the treatment of cognitive decline resulting from Alzheimer's disease, PDE2-Is and PDE9-Is may be better targets in this population than PDE5-Is.

Thirdly, since most PDEs are transcribed by several genes, which give rise to multiple PDE splice variants and isoforms, further investigation into possible isoform-specific effects of PDE-Is is a field of great interest. For example, four isoforms of PDE4 mRNA have been found; PDE4A, PDE4B, PDE4C, and PDE4D. Indirect evidence suggests that PDE4A and PDE4B are involved in signaling pathways related to affective (Ye et al. 2000) and memory (Ahmed and Frey 2003) processes, respectively. Recently, the antidepressant potential of PDE4A in the hippocampus has been found to be related to specific splice variants of this PDE4 isoform (D'Sa et al. 2005). The same probably holds for PDE4B and memory (Ahmed and Frey 2005) or schizophrenia (Siuciak et al. 2008a). PDE4D KO mice have already been generated and these animals display both an antidepressant and procognitive profile (Zhang et al. 2002). Furthermore, it has been observed that the expression of the majority of PDE4D isoforms (1-9) was reduced in the hippocampus of patients with Alzheimer's disease compared to healthy adults. Interestingly, PDE4D1 and PDE4D2 were increased in the brains Alzheimer's patients (McLachlan et al. 2007). These findings underscore the relevance of further investigations into the role of isoform-specific PDEs in cognition enhancement.

Furthermore, the most widely used PDE4-I in behavioral studies, rolipram, produces severe dose-limiting emetic side effects including headache, gastric hypersecretion, and severe emesis (e.g., nausea) in humans (Zhu et al. 2001). Novel PDE4-Is are thought to produce less emetic side effects, but thus far no human cognition studies have been reported using these second-generation PDE4-Is. Thus far, only PDE5-Is can be prescribed to humans. However, particularly cardiovascular effects limit their usefulness as a general treatment for cognitive disorders, since patients with cardiovascular indications cannot be included. In addition, central effects including visual disturbances and headache limit the use of PDE5-I such as sildenafil (Kruuse et al. 2002). Especially chronic treatment with these drugs could be disadvantageous. Again, an isoform-specific PDE-I could circumvent the abovementioned side effects.

\section{Future directions}

In this review, we summarized all recent available literature of the cognition-enhancing effects of PDE-Is in preclinical studies. It has been shown that inhibitors of PDE2, PDE4, PDE5, PDE9, and PDE10 improve a wide range of cognitive processes, including information processing, attention, learning, memory, executive functioning, and response inhibition, in various behavioral models within different species. We argue that it is unlikely that blood flow is the mechanism underlying these procognitive effects. We feel that LTP appears to be a better substrate for the cognition-enhancing properties of PDE-Is.

Despite accumulating evidence for the procognitive effects of PDE-Is, further investigation is still required. First, more localization studies are required to obtain more knowledge about the localization of the specific PDE isoforms in different brain areas. In addition, the exact underlying working mechanisms of selective PDE-Is have to be investigated by using central administration paradigms, blood flow measurements, and parallel LTP experiments. Clearly, it is crucial to translate the procognitive findings in animals to human subjects. Since PDE5-Is are already clinically accepted for the treatment of erectile dysfunction, these drugs can be readily tested in human subjects. Besides neuropsychological 
tasks to address cognitive functioning, imaging studies (EEG and fMRI) are necessary to elucidate the central mechanisms underlying the cognition-enhancing effects of PDE inhibition.

Taken together, PDE-Is offer a promising target for cognitive enhancement. Yet, the future for cognition-enhancing PDE-Is lies in the development of isoform-specific PDE-Is that are present in the aged or Alzheimer-diseased brain and that have limited aversive side effect profiles within the effective dose range for cognition enhancement. Suitable candidates appear to be PDE2-Is or PDE9-Is, although little is known about their side effect profiles and isoform specificity.

AcknowledgementsJ.P. is supported by the EU Framework 6 Integrated Project NEWMOOD (LSHM-CT-2004-503474). In addition, the authors would like to thank Anke Sambeth for her useful comments.

Open Access This article is distributed under the terms of the Creative Commons Attribution Noncommercial License which permits any noncommercial use, distribution, and reproduction in any medium, provided the original author(s) and source are credited.

\section{References}

Abel T, Martin KC, Bartsch D, Kandel ER (1998) Memory suppressor genes: inhibitory constraints on the storage of long-term memory. Science 279:338-341

Ahmed T, Frey JU (2003) Expression of the specific type IV phosphodiesterase gene PDE4B3 during different phases of longterm potentiation in single hippocampal slices of rats in vitro. Neuroscience 117:627-638

Ahmed T, Frey JU (2005) Phosphodiesterase 4B (PDE4B) and cAMPlevel regulation within different tissue fractions of rat hippocampal slices during long-term potentiation in vitro. Brain Res 1041:212222

Andreeva SG, Dikkes P, Epstein PM, Rosenberg PA (2001) Expression of cGMP-specific phosphodiesterase 9A mRNA in the rat brain. J Neurosci 21:9068-9076

Arancio O, Kandel ER, Hawkins RD (1995) Activity-dependent longterm enhancement of transmitter release by presynaptic $3^{\prime}, 5^{\prime}$ cyclic GMP in cultured hippocampal neurons. Nature 376:74-80

Arnavaz A, Aurich A, Weissenborn K, Hartmann U, Emrich HM, Schneider U (2003) Effect of sildenafil (Viagra) on cerebral blood flow velocity: a pilot study. Psychiatry Res 122:207-209

Bach ME, Barad M, Son H, Zhuo M, Lu YF, Shih R, Mansuy I, Hawkins RD, Kandel ER (1999) Age-related defects in spatial memory are correlated with defects in the late phase of hippocampal long-term potentiation in vitro and are attenuated by drugs that enhance the cAMP signaling pathway. Proc Natl Acad Sci U S A 96:5280-5285

Baddeley A (2003) Working memory: looking back and looking forward. Nat Rev Neurosci 4:829-839

Bailey CP, Trejos JA, Schanne FA, Stanton PK (2003) Pairing elevation of [cyclic GMP] with inhibition of PKA produces long-term depression of glutamate release from isolated rat hippocampal presynaptic terminals. Eur J Neurosci 17:903-908

Barad M, Bourtchouladze R, Winder DG, Golan H, Kandel E (1998) Rolipram, a type IV-specific phosphodiesterase inhibitor, facilitates the establishment of long-lasting long-term potentiation and improves memory. Proc Natl Acad Sci U S A 95:15020 15025
Baratti CM, Boccia MM (1999) Effects of sildenafil on long-term retention of an inhibitory avoidance response in mice. Behav Pharmacol 10:731-737

Bender AT, Beavo JA (2006) Cyclic nucleotide phosphodiesterases: molecular regulation to clinical use. Pharmacol Rev 58:488-520

Bernabeu R, Schmitz P, Faillace MP, Izquierdo I, Medina JH (1996) Hippocampal cGMP and cAMP are differentially involved in memory processing of inhibitory avoidance learning. NeuroReport 7:585-588

Best JD, Berghmans S, Hunt JJ, Clarke SC, Fleming A, Goldsmith P, Roach AG (2008) Non-associative learning in larval zebrafish. Neuropsychopharmacology 33:1206-1215

Billingsley ML, Polli JW, Balaban CD, Kincaid RL (1990) Developmental expression of calmodulin-dependent cyclic nucleotide phosphodiesterase in rat brain. Brain Res Dev Brain Res 53:253-263

Blaney PH (1986) Affect and memory: a review. Psychol Bull 99:229-246

Bliss TV, Collingridge GL (1993) A synaptic model of memory: longterm potentiation in the hippocampus. Nature 361:31-39

Blokland A, Schreiber R, Prickaerts J (2006) Improving memory: a role for phosphodiesterases. Curr Pharm Des 12:2511-2523

Boess FG, Hendrix M, van der Staay FJ, Erb C, Schreiber R, van Staveren W, de Vente J, Prickaerts J, Blokland A, Koenig G (2004) Inhibition of phosphodiesterase 2 increases neuronal cGMP, synaptic plasticity and memory performance. Neuropharmacology 47:1081-1092

Bolger GB, Rodgers L, Riggs M (1994) Differential CNS expression of alternative mRNA isoforms of the mammalian genes encoding cAMP-specific phosphodiesterases. Gene 149:237-244

Bourtchouladze R, Lidge R, Catapano R, Stanley J, Gossweiler S, Romashko D, Scott R, Tully T (2003) A mouse model of Rubinstein-Taybi syndrome: defective long-term memory is ameliorated by inhibitors of phosphodiesterase 4. Proc Natl Acad Sci U S A 100:10518-10522

Braun NN, Reutiman TJ, Lee S, Folsom TD, Fatemi SH (2007) Expression of phosphodiesterase 4 is altered in the brains of subjects with autism. NeuroReport 18:1841-1844

Cahill L, Prins B, Weber M, McGaugh JL (1994) Beta-adrenergic activation and memory for emotional events. Nature 371:702-704

Calabresi P, Gubellini P, Centonze D, Sancesario G, Morello M, Giorgi M, Pisani A, Bernardi G (1999) A critical role of the nitric oxide/cGMP pathway in corticostriatal long-term depression. J Neurosci 19:2489-2499

Campbell E, Edwards T (2006) Zaprinast consolidates long-term memory when administered to neonate chicks trained using a weakly reinforced single trial passive avoidance task. Behav Brain Res 169:181-185

Cherry JA, Davis RL (1999) Cyclic AMP phosphodiesterases are localized in regions of the mouse brain associated with reinforcement, movement, and affect. J Comp Neurol 407:287-301

Cherry JA, Thompson BE, Pho V (2001) Diazepam and rolipram differentially inhibit cyclic AMP-specific phosphodiesterases PDE4A1 and PDE4B3 in the mouse. Biochim Biophys Acta 1518:27-35

Cho CH, Cho DH, Seo MR, Juhnn YS (2000) Differential changes in the expression of cyclic nucleotide phosphodiesterase isoforms in rat brains by chronic treatment with electroconvulsive shock. Exp Mol Med 32:110-114

Comery TA, Martone RL, Aschmies S, Atchison KP, Diamantidis G, Gong X, Zhou H, Kreft AF, Pangalos MN, Sonnenberg-Reines J, Jacobsen JS, Marquis KL (2005) Acute gamma-secretase inhibition improves contextual fear conditioning in the $\operatorname{Tg} 2576$ mouse model of Alzheimer's disease. J Neurosci 25:8898-8902

Costa DA, Cracchiolo JR, Bachstetter AD, Hughes TF, Bales KR, Paul SM, Mervis RF, Arendash GW, Potter H (2007) Enrichment improves cognition in $\mathrm{AD}$ mice by amyloid-related and unrelated mechanisms. Neurobiol Aging 28:831-844 
D'Sa C, Eisch AJ, Bolger GB, Duman RS (2005) Differential expression and regulation of the cAMP-selective phosphodiesterase type $4 \mathrm{~A}$ splice variants in rat brain by chronic antidepressant administration. Eur J Neurosci 22:1463-1475

Davis HP, Squire LR (1984) Protein synthesis and memory: a review. Psychol Bull 96:518-559

Dent G, White SR, Tenor H, Bodtke K, Schudt C, Leff AR, Magnussen H, Rabe KF (1998) Cyclic nucleotide phosphodiesterase in human bronchial epithelial cells: characterization of isoenzymes and functional effects of PDE inhibitors. Pulm Pharmacol Ther 11:47-56

Devan BD, Sierra-Mercado D Jr, Jimenez M, Bowker JL, Duffy KB, Spangler EL, Ingram DK (2004) Phosphodiesterase inhibition by sildenafil citrate attenuates the learning impairment induced by blockade of cholinergic muscarinic receptors in rats. Pharmacol Biochem Behav 79:691-699

Devan BD, Bowker JL, Duffy KB, Bharati IS, Jimenez M, SierraMercado D Jr, Nelson CM, Spangler EL, Ingram DK (2006) Phosphodiesterase inhibition by sildenafil citrate attenuates a maze learning impairment in rats induced by nitric oxide synthase inhibition. Psychopharmacology (Berl) 183:439-445

Devan BD, Pistell PJ, Daffin LW Jr, Nelson CM, Duffy KB, Bowker JL, Bharati IS, Sierra-Mercado D, Spangler EL, Ingram DK (2007) Sildenafil citrate attenuates a complex maze impairment induced by intracerebroventricular infusion of the NOS inhibitor N(omega)nitro-L-arginine methyl ester. Eur J Pharmacol 563:134-140

DeZazzo J, Tully T (1995) Dissection of memory formation: from behavioral pharmacology to molecular genetics. Trends Neurosci 18:212-218

Domek-Lopacinska K, Strosznajder JB (2008) The effect of selective inhibition of cyclic GMP hydrolyzing phosphodiesterases 2 and 5 on learning and memory processes and nitric oxide synthase activity in brain during aging. Brain Res 1216:68-77

Dundore RL, Clas DM, Wheeler LT, Habeeb PG, Bode DC, Buchholz RA, Silver PJ, Pagani ED (1993) Zaprinast increases cyclic GMP levels in plasma and in aortic tissue of rats. Eur J Pharmacol 249:293-297

Edwards TM, Lindley N (2007) Phosphodiesterase type 5 inhibition coupled to strong reinforcement results in two periods of transient retention loss in the young chick. Behav Brain Res 183:231-235

Egawa T, Mishima K, Matsumoto Y, Iwasaki K, Fujiwara M (1997) Rolipram and its optical isomers, phosphodiesterase 4 inhibitors, attenuated the scopolamine-induced impairments of learning and memory in rats. Jpn J Pharmacol 75:275-281

Erceg S, Monfort P, Hernandez-Viadel M, Llansola M, Montoliu C, Felipo V (2005a) Restoration of learning ability in hyperammonemic rats by increasing extracellular cGMP in brain. Brain Res 1036:115-121

Erceg S, Monfort P, Hernandez-Viadel M, Rodrigo R, Montoliu C, Felipo $\mathrm{V}(2005 \mathrm{~b})$ Oral administration of sildenafil restores learning ability in rats with hyperammonemia and with portacaval shunts. Hepatology 41:299-306

Erceg S, Monfort P, Cauli O, Montoliu C, Llansola M, Piedrafita B, Felipo V (2006) Role of extracellular cGMP and of hyperammonemia in the impairment of learning in rats with chronic hepatic failure. Therapeutic implications. Neurochem Int 48:441-446

Fawcett L, Baxendale R, Stacey P, McGrouther C, Harrow I, Soderling S, Hetman J, Beavo JA, Phillips SC (2000) Molecular cloning and characterization of a distinct human phosphodiesterase gene family: PDE11A. Proc Natl Acad Sci U S A 97:3702-3707

Fisher DA, Smith JF, Pillar JS, St Denis SH, Cheng JB (1998a) Isolation and characterization of PDE8A, a novel human cAMPspecific phosphodiesterase. Biochem Biophys Res Commun 246:570-577

Fisher DA, Smith JF, Pillar JS, St Denis SH, Cheng JB (1998b) Isolation and characterization of PDE9A, a novel human cGMPspecific phosphodiesterase. J Biol Chem 273:15559-15564
Frith C (1996) Neuropsychology of schizophrenia, what are the implications of intellectual and experiential abnormalities for the neurobiology of schizophrenia? Br Med Bull 52:618-626

Fujishige K, Kotera J, Michibata H, Yuasa K, Takebayashi S, Okumura K, Omori K (1999) Cloning and characterization of a novel human phosphodiesterase that hydrolyzes both cAMP and cGMP (PDE10A). J Biol Chem 274:18438-18445

Fujita M, Imaizumi M, D’Sa C, Zoghbi SS, Crescenzo MS, Hong J, Musachio JL, Gee AD, Seidel J, Green MV, Pike VW, Duman RS, Innis RB (2007) In vivo and in vitro measurement of brain phosphodiesterase 4 in rats after antidepressant administration. Synapse 61:78-86

Gamanuma M, Yuasa K, Sasaki T, Sakurai N, Kotera J, Omori K (2003) Comparison of enzymatic characterization and gene organization of cyclic nucleotide phosphodiesterase 8 family in humans. Cell Signal 15:565-574

Ghelardini C, Galeotti N, Gualtieri F, Romanelli MN, Bucherelli C, Baldi E, Bartolini A (2002) DM235 (sunifiram): a novel nootropic with potential as a cognitive enhancer. Naunyn Schmiedebergs Arch Pharmacol 365:419-426

Giordano D, De Stefano ME, Citro G, Modica A, Giorgi M (2001) Expression of cGMP-binding cGMP-specific phosphodiesterase (PDE5) in mouse tissues and cell lines using an antibody against the enzyme amino-terminal domain. Biochim Biophys Acta 1539:16-27

Gong B, Vitolo OV, Trinchese F, Liu S, Shelanski M, Arancio O (2004) Persistent improvement in synaptic and cognitive functions in an Alzheimer mouse model after rolipram treatment. $\mathrm{J}$ Clin Invest 114:1624-1634

Grass H, Klotz T, Fathian-Sabet B, Berghaus G, Engelmann U, Kaferstein H (2001) Sildenafil (Viagra): is there an influence on psychological performance? Int Urol Nephrol 32:409-412

Griffiths S, Scott H, Glover C, Bienemann A, Ghorbel MT, Uney J, Brown MW, Warburton EC, Bashir ZI (2008) Expression of longterm depression underlies visual recognition memory. Neuron 58:186-194

Halene TB, Siegel SJ (2008) Antipsychotic-like properties of phosphodiesterase 4 inhibitors: evaluation of 4-(3-butoxy-4-methoxybenzyl)-2-imidazolidinone (RO-20-1724) with auditory event-related potentials and prepulse inhibition of startle. J Pharmacol Exp Ther 326:230-239

Hayashi M, Matsushima K, Ohashi $\mathrm{H}$, Tsunoda H, Murase S, Kawarada Y, Tanaka T (1998) Molecular cloning and characterization of human PDE8B, a novel thyroid-specific isozyme of 3',5'-cyclic nucleotide phosphodiesterase. Biochem Biophys Res Commun 250:751-756

Hayashi M, Shimada Y, Nishimura Y, Hama T, Tanaka T (2002) Genomic organization, chromosomal localization, and alternative splicing of the human phosphodiesterase 8B gene. Biochem Biophys Res Commun 297:1253-1258

Hebb AL, Robertson HA, Denovan-Wright EM (2008) Phosphodiesterase $10 \mathrm{~A}$ inhibition is associated with locomotor and cognitive deficits and increased anxiety in mice. Eur Neuropsychopharmacol 18:339-363

Hetman JM, Soderling SH, Glavas NA, Beavo JA (2000) Cloning and characterization of PDE7B, a cAMP-specific phosphodiesterase. Proc Natl Acad Sci U S A 97:472-476

Holthues H, Vollrath L (2004) The phototransduction cascade in the isolated chick pineal gland revisited. Brain Res 999:175-180

Hotston M, Jeremy JY, Bloor J, Greaves NS, Persad R, Angelini G, Shukla N (2007) Homocysteine and copper interact to promote type 5 phosphodiesterase expression in rabbit cavernosal smooth muscle cells: mediation by superoxide and inhibition with sildenafil. Asian J Androl (in press)

Huang Z, Dias R, Jones T, Liu S, Styhler A, Claveau D, Otu F, Ng K, Laliberte F, Zhang L, Goetghebeur P, Abraham WM, Macdonald D, Dube D, Gallant M, Lacombe P, Girard Y, Young RN, Turner 
MJ, Nicholson DW, Mancini JA (2007) L-454,560, a potent and selective PDE4 inhibitor with in vivo efficacy in animal models of asthma and cognition. Biochem Pharmacol 73:1971-1981

Imanishi T, Sawa A, Ichimaru Y, Miyashiro M, Kato S, Yamamoto T, Ueki S (1997) Ameliorating effects of rolipram on experimentally induced impairments of learning and memory in rodents. Eur J Pharmacol 321:273-278

Impey S, Mark M, Villacres EC, Poser S, Chavkin C, Storm DR (1996) Induction of CRE-mediated gene expression by stimuli that generate long-lasting LTP in area CA1 of the hippocampus. Neuron 16:973-982

Ishikawa M, Hosoi R, Kobayashi K, Nishimura T, Inoue O (2002) Rolipram depresses [(3)H]2-deoxyglucose uptake in mouse brain and heart in vivo. Eur J Nucl Med Mol Imaging 29:12121215

Ito M, Nishikawa M, Fujioka M, Miyahara M, Isaka N, Shiku H, Nakano T (1996) Characterization of the isoenzymes of cyclic nucleotide phosphodiesterase in human platelets and the effects of E4021. Cell Signal 8:575-581

Izquierdo I, Barros DM, Mello e Souza T, de Souza MM, Izquierdo LA, Medina JH (1998) Mechanisms for memory types differ. Nature 393:635-636

Izquierdo LA, Barros DM, Vianna MR, Coitinho A, deDavid e Silva T, Choi H, Moletta B, Medina JH, Izquierdo I (2002) Molecular pharmacological dissection of short- and long-term memory. Cell Mol Neurobiol 22:269-287

Izquierdo I, Bevilaqua LR, Rossato JI, Bonini JS, Medina JH, Cammarota M (2006) Different molecular cascades in different sites of the brain control memory consolidation. Trends Neurosci 29:496-505

Kanes SJ, Tokarczyk J, Siegel SJ, Bilker W, Abel T, Kelly MP (2007) Rolipram: a specific phosphodiesterase 4 inhibitor with potential antipsychotic activity. Neuroscience 144:239-246

Kesner RP, Hopkins RO (2006) Mnemonic functions of the hippocampus: a comparison between animals and humans. Biol Psychol 73:3-18

Kobayashi T, Gamanuma M, Sasaki T, Yamashita Y, Yuasa K, Kotera J, Omori K (2003) Molecular comparison of rat cyclic nucleotide phosphodiesterase 8 family: unique expression of PDE8B in rat brain. Gene 319:21-31

Kotera J, Fujishige K, Omori K (2000) Immunohistochemical localization of cGMP-binding cGMP-specific phosphodiesterase (PDE5) in rat tissues. J Histochem Cytochem 48:685-693

Krukoff TL (1998) Central regulation of autonomic function: no brakes? Clin Exp Pharmacol Physiol 25:474-478

Kruuse C, Thomsen LL, Jacobsen TB, Olesen J (2002) The phosphodiesterase 5 inhibitor sildenafil has no effect on cerebral blood flow or blood velocity, but nevertheless induces headache in healthy subjects. J Cereb Blood Flow Metab 22:1124-1131

Kurt M, Bilge SS, Aksoz E, Kukula O, Celik S, Kesim Y (2004) Effect of sildenafil on anxiety in the plus-maze test in mice. Pol J Pharmacol 56:353-357

Lal S, Sharma RK, McGregor C, Macaulay RJ (1999) Immunohistochemical localization of calmodulin-dependent cyclic phosphodiesterase in the human brain. Neurochem Res 24:43-49

Loughney K, Snyder PB, Uher L, Rosman GJ, Ferguson K, Florio VA (1999) Isolation and characterization of PDE10A, a novel human 3', 5'-cyclic nucleotide phosphodiesterase. Gene 234:109-117

Lu YF, Kandel ER, Hawkins RD (1999) Nitric oxide signaling contributes to late-phase LTP and CREB phosphorylation in the hippocampus. J Neurosci 19:10250-10261

Malenka RC (1994) Synaptic plasticity in the hippocampus: LTP and LTD. Cell 78:535-538

Martins TJ, Mumby MC, Beavo JA (1982) Purification and characterization of a cyclic GMP-stimulated cyclic nucleotide phosphodiesterase from bovine tissues. J Biol Chem 257:1973-1979
Mattson MP, Chan SL, Duan W (2002) Modification of brain aging and neurodegenerative disorders by genes, diet, and behavior. Physiol Rev 82:637-672

McGaugh JL (1989) Dissociating learning and performance: drug and hormone enhancement of memory storage. Brain Res Bull 23:339 345

McLachlan CS, Chen ML, Lynex CN, Goh DL, Brenner S, Tay SK (2007) Changes in PDE4D isoforms in the hippocampus of a patient with advanced Alzheimer disease. Arch Neurol 64:456457

Merck and Co. (2006) MK0952 in patients with mild-to-moderate Alzheimer's disease. Available at http://clinicaltrials.gov/show/ NCT00362024

Messier C (2004) Glucose improvement of memory: a review. Eur J Pharmacol 490:33-57

Milman HA, Arnold SB (2002) Neurologic, psychological, and aggressive disturbances with sildenafil. Ann Pharmacother 36:1129-1134

Miro X, Perez-Torres S, Palacios JM, Puigdomenech P, Mengod G (2001) Differential distribution of cAMP-specific phosphodiesterase 7A mRNA in rat brain and peripheral organs. Synapse 40:201-214

Monti B, Berteotti C, Contestabile A (2006) Subchronic rolipram delivery activates hippocampal CREB and Arc, enhances retention and slows down extinction of conditioned fear. Neuropsychopharmacology 31:278-286

Morin F, Lugnier C, Kameni J, Voisin P (2001) Expression and role of phosphodiesterase 6 in the chicken pineal gland. J Neurochem 78:88-99

Murad F, Mittal CK, Arnold WP, Katsuki S, Kimura H (1978) Guanylate cyclase: activation by azide, nitro compounds, nitric oxide, and hydroxyl radical and inhibition by hemoglobin and myoglobin. Adv Cycl Nucleotide Res 9:145-158

Nagakura A, Niimura M, Takeo S (2002) Effects of a phosphodiesterase IV inhibitor rolipram on microsphere embolism-induced defects in memory function and cerebral cyclic AMP signal transduction system in rats. Br J Pharmacol 135:1783-1793

Navakkode S, Sajikumar S, Frey JU (2004) The type IV-specific phosphodiesterase inhibitor rolipram and its effect on hippocampal longterm potentiation and synaptic tagging. J Neurosci 24:7740-7744

Navakkode S, Sajikumar S, Frey JU (2005) Mitogen-activated protein kinase-mediated reinforcement of hippocampal early long-term depression by the type IV-specific phosphodiesterase inhibitor rolipram and its effect on synaptic tagging. J Neurosci 25:10664 10670

Nguyen PV, Woo NH (2003) Regulation of hippocampal synaptic plasticity by cyclic AMP-dependent protein kinases. Prog Neurobiol 71:401-37

Niles LP, Wang J (1999) Diazepam inhibits forskolin-stimulated adenylyl cyclase activity in human tumour cells. Pharmacol Toxicol 85:153-156

Pang PT, Teng HK, Zaitsev E, Woo NT, Sakata K, Zhen S, Teng KK, Yung WH, Hempstead BL, Lu B (2004) Cleavage of proBDNF by $\mathrm{tPA} /$ plasmin is essential for long-term hippocampal plasticity. Science 306:487-491

Parrott A, Morinan A, Moss M, Scholey A (2004) Understanding drugs and behaviour. Wiley, Chichester, UK

Paterno R, Faraci FM, Heistad DD (1996) Role of Ca(2+)-dependent $\mathrm{K}+$ channels in cerebral vasodilatation induced by increases in cyclic GMP and cyclic AMP in the rat. Stroke 27:1603-1607 (discussion 1607-1608)

Patil CS, Jain NK, Singh VP, Kulkarni SK (2004a) Differential effect of the PDE5 inhibitors, sildenafil and zaprinast, in aging- and lippolysaccharide-induced cognitive dysfunction in mice. Drug Dev Res 63:66-75

Patil CS, Singh VP, Singh S, Kulkarni SK (2004b) Modulatory effect of the PDE-5 inhibitor sildenafil in diabetic neuropathy. Pharmacology 72:192-195 
Patil CS, Singh VP, Kulkarni SK (2006) Modulatory effect of sildenafil in diabetes and electroconvulsive shock-induced cognitive dysfunction in rats. Pharmacol Rep 58:373-380

Perez-Torres S, Miro X, Palacios JM, Cortes R, Puigdomenech P, Mengod G (2000) Phosphodiesterase type 4 isozymes expression in human brain examined by in situ hybridization histochemistry and $[3 \mathrm{H}]$ rolipram binding autoradiography. Comparison with monkey and rat brain. J Chem Neuroanat 20:349-374

Perez-Torres S, Cortes R, Tolnay M, Probst A, Palacios JM, Mengod G (2003) Alterations on phosphodiesterase type 7 and 8 isozyme mRNA expression in Alzheimer's disease brains examined by in situ hybridization. Exp Neurol 182:322-334

Polli JW, Kincaid RL (1994) Expression of a calmodulin-dependent phosphodiesterase isoform (PDE1B1) correlates with brain regions having extensive dopaminergic innervation. J Neurosci 14:1251-1261

Prickaerts J, Steckler T (2005) Effects of glucocorticoids on emotion and memory processes in animals. In: Steckler T, Kalin N, Reul JMHM (eds) Handbook of stress and the brain, part 1: the neurobiology of stress. Elsevier, Amsterdam, pp 359-386

Prickaerts J, Steinbusch HW, Smits JF, de Vente J (1997) Possible role of nitric oxide-cyclic GMP pathway in object recognition memory: effects of 7-nitroindazole and zaprinast. Eur J Pharmacol 337:125-136

Prickaerts J, de Vente J, Honig W, Steinbusch HW, Blokland A (2002a) cGMP, but not cAMP, in rat hippocampus is involved in early stages of object memory consolidation. Eur J Pharmacol 436:83-87

Prickaerts J, van Staveren WC, Sik A, Markerink-van Ittersum M, Niewohner U, van der Staay FJ, Blokland A, de Vente J (2002b) Effects of two selective phosphodiesterase type 5 inhibitors, sildenafil and vardenafil, on object recognition memory and hippocampal cyclic GMP levels in the rat. Neuroscience 113:351-361

Prickaerts J, Sik A, van Staveren WC, Koopmans G, Steinbusch HW, van der Staay FJ, de Vente J, Blokland A (2004) Phosphodiesterase type 5 inhibition improves early memory consolidation of object information. Neurochem Int 45:915-928

Prickaerts J, Sik A, van der Staay FJ, de Vente J, Blokland A (2005) Dissociable effects of acetylcholinesterase inhibitors and phosphodiesterase type 5 inhibitors on object recognition memory: acquisition versus consolidation. Psychopharmacology (Berl) 177:381-390

Ramos BP, Birnbaum SG, Lindenmayer I, Newton SS, Duman RS, Arnsten AF (2003) Dysregulation of protein kinase a signaling in the aged prefrontal cortex: new strategy for treating age-related cognitive decline. Neuron 40:835-845

Ramos BP, Stark D, Verduzco L, van Dyck CH, Arnsten AF (2006) Alpha2A-adrenoceptor stimulation improves prefrontal cortical regulation of behavior through inhibition of cAMP signaling in aging animals. Learn Mem 13:770-776

Randt CT, Judge ME, Bonnet KA, Quartermain D (1982) Brain cyclic AMP and memory in mice. Pharmacol Biochem Behav 17:677680

Reed TM, Browning JE, Blough RI, Vorhees CV, Repaske DR (1998) Genomic structure and chromosome location of the murine PDE1B phosphodiesterase gene. Mamm Genome 9:571-576

Rehse K, Scheffler H, Reitner N (1999) Interaction of Viagra with the NO donors molsidomine and RE 2047 with regard to antithrombotic and blood pressure lowering activities. Arch Pharm (Weinh) 332:182-184

Reinhardt RR, Chin E, Zhou J, Taira M, Murata T, Manganiello VC, Bondy CA (1995) Distinctive anatomical patterns of gene expression for cGMP-inhibited cyclic nucleotide phosphodiesterases. J Clin Invest 95:1528-1538

Rentero C, Monfort A, Puigdomenech P (2003) Identification and distribution of different mRNA variants produced by differential splicing in the human phosphodiesterase 9A gene. Biochem Biophys Res Commun 301:686-692
Repaske DR, Corbin JG, Conti M, Goy MF (1993) A cyclic GMPstimulated cyclic nucleotide phosphodiesterase gene is highly expressed in the limbic system of the rat brain. Neuroscience 56:673-686

Reyes-Irisarri E, Markerink-Van Ittersum M, Mengod G, de Vente J (2007) Expression of the cGMP-specific phosphodiesterases 2 and 9 in normal and Alzheimer's disease human brains. Eur J Neurosci 25:3332-3338

Reyes-Irisarri E, Perez-Torres S, Miro X, Martinez E, Puigdomenech P, Palacios JM, Mengod G (2008) Differential distribution of PDE4B splice variant mRNAs in rat brain and the effects of systemic administration of LPS in their expression. Synapse 62:74-9

Reymann KG, Frey JU (2007) The late maintenance of hippocampal LTP: requirements, phases, 'synaptic tagging', 'late-associativity' and implications. Neuropharmacology 52:24-40

Richter W, Jin SL, Conti M (2005) Splice variants of the cyclic nucleotide phosphodiesterase PDE4D are differentially expressed and regulated in rat tissue. Biochem J 388:803-811

Rodefer JS, Murphy ER, Baxter MG (2005) PDE10A inhibition reverses subchronic PCP-induced deficits in attentional set-shifting in rats. Eur J Neurosci 21:1070-1076

Rutten K, Vente JD, Sik A, Ittersum MM, Prickaerts J, Blokland A (2005) The selective PDE5 inhibitor, sildenafil, improves object memory in Swiss mice and increases cGMP levels in hippocampal slices. Behav Brain Res 164:11-16

Rutten K, Prickaerts J, Blokland A (2006) Rolipram reverses scopolamine-induced and time-dependent memory deficits in object recognition by different mechanisms of action. Neurobiol Learn Mem 85:132-138

Rutten K, Lieben C, Smits L, Blokland A (2007a) The PDE4 inhibitor rolipram reverses object memory impairment induced by acute tryptophan depletion in the rat. Psychopharmacology (Berl) 192:275-282

Rutten K, Prickaerts J, Hendrix M, van der Staay FJ, Sik A, Blokland A (2007b) Time-dependent involvement of cAMP and cGMP in consolidation of object memory: studies using selective phosphodiesterase type 2, 4 and 5 inhibitors. Eur J Pharmacol 558:107-112

Rutten K, Basile JL, Prickaerts J, Blokland A, Vivian JA (2008a) Selective PDE inhibitors rolipram and sildenafil improve object retrieval performance in adult cynomolgus macaques. Psychopharmacology (Berl) 196:643-648

Rutten K, Misner DL, Works M, Blokland A, Novak TJ, Santarelli L, Wallace-Boone T (2008b) Enhanced long-term potentiation and impaired learning in phosphodiesterase 4D knockout (PDE4D-/-) mice. Eur J Neurosci (in press)

Rutten K, Prickaerts J, Schaenzle G, Rosenbrock H, Blokland A (2008c) Sub-chronic rolipram treatment leads to a persistent improvement in long-term object memory in rats. Neurobiol Learn Mem. doi:10.1016/j.nlm.2008.04.016

Salanova M, Chun SY, Iona S, Puri C, Stefanini M, Conti M (1999) Type 4 cyclic adenosine monophosphate-specific phosphodiesterases are expressed in discrete subcellular compartments during rat spermiogenesis. Endocrinology 140:2297-2306

Sasaki T, Kotera J, Omori K (2002) Novel alternative splice variants of rat phosphodiesterase $7 \mathrm{~B}$ showing unique tissue-specific expression and phosphorylation. Biochem J 361:211-220

Schmidt HH, Lohmann SM, Walter U (1993) The nitric oxide and cGMP signal transduction system: regulation and mechanism of action. Biochim Biophys Acta 1178:153-175

Schmidt CJ, Chapin DS, Cianfrogna J, Corman ML, Hajos M, Harms JF, Hoffman WE, Lebel LA, McCarthy SA, Nelson FR, ProulxLafrance C, Majchrzak MJ, Ramirez AD, Schmidt K, Seymour PA, Siuciak JA, Tingley Iii FD, Williams RD, Verhoest PR, Menniti FS (2008) Preclinical characterization of selective PDE10A inhibitors: a new therapeutic approach to the treatment of schizophrenia. J Pharmacol Exp Ther 325:681-690 
Schoffelmeer AN, Wardeh G, Mulder AH (1985) Cyclic AMP facilitates the electrically evoked release of radiolabelled noradrenaline, dopamine and 5-hydroxytryptamine from rat brain slices. Naunyn Schmiedebergs Arch Pharmacol 330:74-76

Schultheiss D, Muller SV, Nager W, Stief CG, Schlote N, Jonas U, Asvestis C, Johannes S, Munte TF (2001) Central effects of sildenafil (Viagra) on auditory selective attention and verbal recognition memory in humans: a study with event-related brain potentials. World J Urol 19:46-50

Seeger TF, Bartlett B, Coskran TM, Culp JS, James LC, Krull DL, Lanfear J, Ryan AM, Schmidt CJ, Strick CA, Varghese AH, Williams RD, Wylie PG, Menniti FS (2003) Immunohistochemical localization of PDE10A in the rat brain. Brain Res 985:113-126

Setter SM, Iltz JL, Fincham JE, Campbell RK, Baker DE (2005) Phosphodiesterase 5 inhibitors for erectile dysfunction. Ann Pharmacother 39:1286-1295

Shafiei M, Mahmoudian M, Rostami P, Nemati F (2006) Effect of sildenafil (Viagra) on memory retention of a passive avoidance response in rats. Acta Physiol Hung 93:53-59

Shah BH, Catt KJ (2004) GPCR-mediated transactivation of RTKs in the CNS: mechanisms and consequences. Trends Neurosci 27:48-53

Shakur Y, Holst LS, Landstrom TR, Movsesian M, Degerman E, Manganiello V (2001) Regulation and function of the cyclic nucleotide phosphodiesterase (PDE3) gene family. Prog Nucleic Acid Res Mol Biol 66:241-277

Silvestre JS, Fernandez AG, Palacios JM (1999) Effects of rolipram on the elevated plus-maze test in rats: a preliminary study. J Psychopharmacol 13:274-277

Singh N, Parle M (2003) Sildenafil improves acquisition and retention of memory in mice. Indian J Physiol Pharmacol 47:318-324

Siuciak JA, McCarthy SA, Chapin DS, Fujiwara RA, James LC, Williams RD, Stock JL, McNeish JD, Strick CA, Menniti FS, Schmidt CJ (2006) Genetic deletion of the striatum-enriched phosphodiesterase PDE10A: evidence for altered striatal function. Neuropharmacology 51:374-385

Siuciak JA, Chapin DS, McCarthy SA, Martin AN (2007) Antipsychotic profile of rolipram: efficacy in rats and reduced sensitivity in mice deficient in the phosphodiesterase-4B (PDE4B) enzyme. Psychopharmacology (Berl) 192:415-424

Siuciak JA, McCarthy SA, Chapin DS, Martin AN (2008a) Behavioral and neurochemical characterization of mice deficient in the phosphodiesterase-4B (PDE4B) enzyme. Psychopharmacology (Berl) 197:115-126

Siuciak JA, McCarthy SA, Chapin DS, Martin AN, Harms JF, Schmidt CJ (2008b) Behavioral characterization of mice deficient in the phosphodiesterase-10A (PDE10A) enzyme on a C57/B16N congenic background. Neuropharmacology 54:417-427

Soderling SH, Bayuga SJ, Beavo JA (1998) Identification and characterization of a novel family of cyclic nucleotide phosphodiesterases. J Biol Chem 273:15553-15558

Soderling SH, Bayuga SJ, Beavo JA (1999) Isolation and characterization of a dual-substrate phosphodiesterase gene family: PDE10A. Proc Natl Acad Sci U S A 96:7071-7076

Sonnenburg WK, Rybalkin SD, Bornfeldt KE, Kwak KS, Rybalkina IG, Beavo JA (1998) Identification, quantitation, and cellular localization of PDE1 calmodulin-stimulated cyclic nucleotide phosphodiesterases. Methods 14:3-19

Stearns G, Evangelista M, Fadool JM, Brockerhoff SE (2007) A mutation in the cone-specific pde6 gene causes rapid cone photoreceptor degeneration in zebrafish. J Neurosci 27:13866-13874
Sweatt JD (1999) Toward a molecular explanation for long-term potentiation. Learn Mem 6:399-416

Tang AH, Franklin SR, Carter DB, Sethy VH, Needham LM, Jacobsen EJ, Von Voigtlander PF (1997) Anxiolytic-like effects of PNU-101017, a partial agonist at the benzodiazepine receptor. Psychopharmacology (Berl) 131:255-263

Uthayathas S, Parameshwaran K, Karuppagounder S, Ilbasmis Tamer I, Degim T, Suppiramaniam V, Dhanasekaran M (2007) Phosphodiesterase 5 inhibition enhances hippocampal long term potentiation in mice. Program No. 936.14.2007. Neuroscience Meeting Planner. Society for Neuroscience, San Diego, CA

Van der Staay FJ, Rutten K, Barfacker L, De Vry J, Erb C, Heckroth H, Karthaus D, Tersteegen A, Van Kampen M, Blokland A, Prickaerts J, Reymann KG, Schroder UH, Hendrix M (2008) The novel selective PDE9 inhibitor BAY 73-6691 improves learning and memory in rodents. Neuropharmacology (in press)

van Staveren WC, Markerink-van Ittersum M (2005) Localization of cyclic guanosine $3^{\prime}, 5^{\prime}$-monophosphate-hydrolyzing phosphodiesterase type 9 in rat brain by nonradioactive in situ hydridization. Methods Mol Biol 307:75-84

Van Staveren WC, Steinbusch HW, Markerink-Van Ittersum M, Repaske DR, Goy MF, Kotera J, Omori K, Beavo JA, De Vente J (2003) mRNA expression patterns of the cGMP-hydrolyzing phosphodiesterases types 2, 5, and 9 during development of the rat brain. J Comp Neurol 467:566-580

van Staveren WC, Steinbusch HW, Markerink-van Ittersum M, Behrends S, de Vente J (2004) Species differences in the localization of cGMPproducing and NO-responsive elements in the mouse and rat hippocampus using cGMP immunocytochemistry. Eur J Neurosci 19:2155-2168

Wang P, Wu P, Egan RW, Billah MM (2001) Human phosphodiesterase $8 \mathrm{~A}$ splice variants: cloning, gene organization, and tissue distribution. Gene 280:183-194

Wang P, Wu P, Egan RW, Billah MM (2003) Identification and characterization of a new human type 9 cGMP-specific phosphodiesterase splice variant (PDE9A5). Differential tissue distribution and subcellular localization of PDE9A variants. Gene $314: 15-27$

Wunder F, Tersteegen A, Rebmann A, Erb C, Fahrig T, Hendrix M (2005) Characterization of the first potent and selective PDE9 inhibitor using a cGMP reporter cell line. Mol Pharmacol 68:1775-1181

Yan C, Bentley JK, Sonnenburg WK, Beavo JA (1994) Differential expression of the $61 \mathrm{kDa}$ and $63 \mathrm{kDa}$ calmodulin-dependent phosphodiesterases in the mouse brain. J Neurosci 14:973-984

Yan C, Zhao AZ, Bentley JK, Beavo JA (1996) The calmodulindependent phosphodiesterase gene PDE1C encodes several functionally different splice variants in a tissue-specific manner. J Biol Chem 271:25699-25706

Yanaka N, Kotera J, Ohtsuka A, Akatsuka H, Imai Y, Michibata H, Fujishige K, Kawai E, Takebayashi S, Okumura K, Omori K (1998) Expression, structure and chromosomal localization of the human cGMP-binding cGMP-specific phosphodiesterase PDE5A gene. Eur J Biochem 255:391-399

Ye Y, Jackson K, O'Donnell JM (2000) Effects of repeated antidepressant treatment of type $4 \mathrm{~A}$ phosphodiesterase (PDE4A) in rat brain. J Neurochem 74:1257-1262

Zhang HT, O'Donnell JM (2000) Effects of rolipram on scopolamineinduced impairment of working and reference memory in the radial-arm maze tests in rats. Psychopharmacology (Berl) 150:311-316 
Zhang HT, Crissman AM, Dorairaj NR, Chandler LJ, O'Donnell JM (2000) Inhibition of cyclic AMP phosphodiesterase (PDE4) reverses memory deficits associated with NMDA receptor antagonism. Neuropsychopharmacology 23:198-204

Zhang HT, Huang Y, Jin SL, Frith SA, Suvarna N, Conti M, O'Donnell JM (2002) Antidepressant-like profile and reduced sensitivity to rolipram in mice deficient in the PDE4D phosphodiesterase enzyme. Neuropsychopharmacology 27:587-595

Zhang HT, Zhao Y, Huang Y, Dorairaj NR, Chandler LJ, O'Donnell JM (2004) Inhibition of the phosphodiesterase 4 (PDE4) enzyme reverses memory deficits produced by infusion of the MEK inhibitor U0126 into the CA1 subregion of the rat hippocampus. Neuropsychopharmacology 29:1432-1439

Zhang HT, Huang Y, Suvarna NU, Deng C, Crissman AM, Hopper AT, De Vivo M, Rose GM, O'Donnell JM (2005) Effects of the novel PDE4 inhibitors MEM1018 and MEM1091 on memory in the radial-arm maze and inhibitory avoidance tests in rats. Psychopharmacology (Berl) 179:613-619

Zhu J, Mix E, Winblad B (2001) The antidepressant and antiinflammatory effects of rolipram in the central nervous system. CNS Drug Rev 7:387-98 